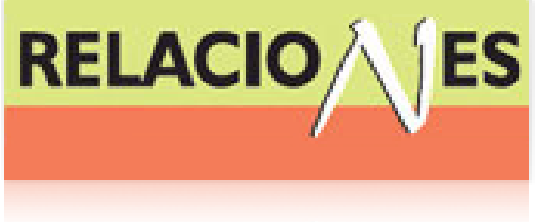

Relaciones. Estudios de historia y sociedad ISSN: 0185-3929

relacion@colmich.edu.mx

El Colegio de Michoacán, A.C

México

Doesburg, Sebastián van

ASENTAMIENTO Y TRANSICIÓN EN EL LIENZO DE SAN JERÓNIMO OTLA, COIXTLAHUACA

Relaciones. Estudios de historia y sociedad, vol. XXXI, núm. 122, 2010, pp. 55-105

El Colegio de Michoacán, A.C

Zamora, México

Disponible en: http://www.redalyc.org/articulo.oa?id=13715892003

- Cómo citar el artículo

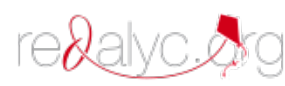

- Número completo

- Más información del artículo

Página de la revista en redalyc.org

Sistema de Información Científica

Red de Revistas Científicas de América Latina, el Caribe, España y Portugal

Proyecto académico sin fines de lucro, desarrollado bajo la iniciativa de acceso abierto 


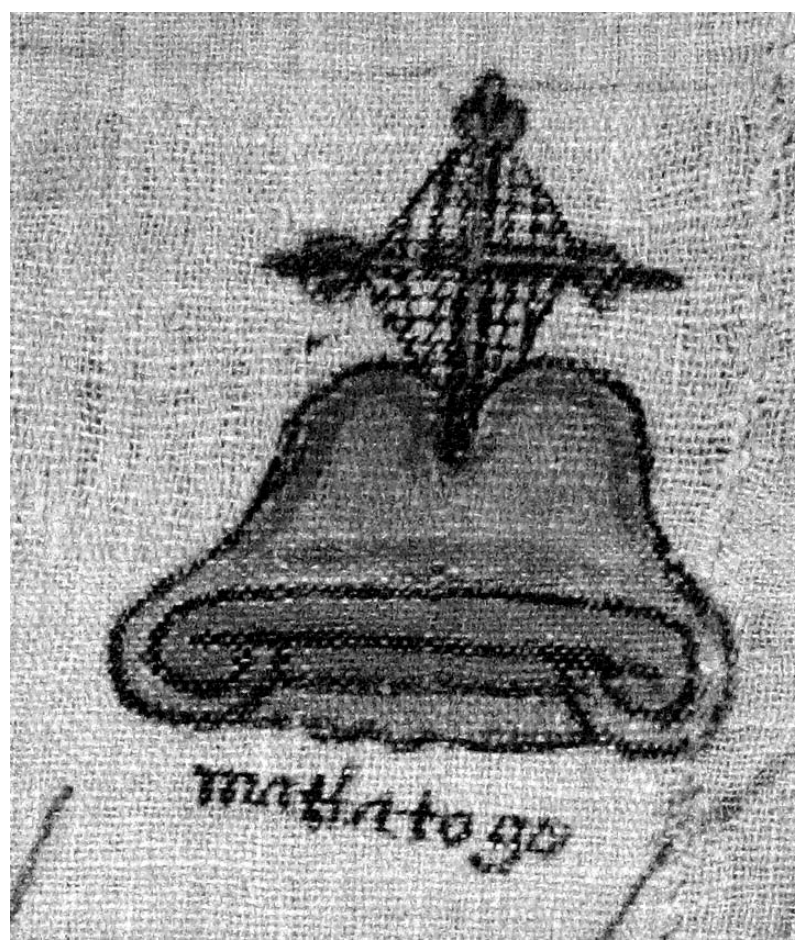

SECCIÓN Z TEMÁTICA 


\title{
ASENTAMIENTO Y TRANSICIÓN EN EL LIENZO DE SAN JERÓNIMO OTLA, COIXTLAHUACA
}

\author{
Sebastián van Doesburg \\ Biblioteca Francisco de Burgoa, UABJO
}

\begin{abstract}
Recientemente, se dio a conocer la existencia de un lienzo pictográfico en la comunidad de San Jerónimo Otla, una agencia de Coixtlahuaca. El documento es el decimotercer texto del llamado "Grupo Coixtlahuaca". En esta contribución se describe el lienzo y se busca contextualizarlo con la ayuda de la documentación archivística existente y a través de la comparación con los otros documentos del mismo grupo. Se analizan varios temas relacionados con la dramática transformación de la comunidad a raíz de las reorganizaciones y redefiniciones llevadas a cabo durante el siglo XVI. La información más antigua se refiere a las relaciones entre los nobles de Otla y uno de los fundadores de Coixtlahuaca en el siglo XIII, quizás reflejando la ayuda de estos nobles en la conquista de la parte sur de la cuenca. Las datos más recientes refieren a la creación del actual pueblo en 1591 a raíz de una separación de una congregación anterior del año de 1556.
\end{abstract}

(Coixtlahuaca, pictografía, códices y lienzos, congregaciones, linderos)

Introducción

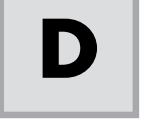

urante los últimos siglos anteriores a la conquista española, la sociedad mixteca y chochona estaba organizada en unidades sociopolíticas llamadas yuhuitayu en mixteco o ñiñasitnau en chochona (ambos términos traducidos como "petate y asiento"). ${ }^{1}$

*basborb@hotmail.com Durante la visita a la comunidad de San Jerónimo Otla en abril de 2008, me acompañó Michel Oudijk, investigador del Instituto de Investigaciones Filológicas de la UNAM. Las fotos incluidas en el presente artículo son de su autoría. Agradezco los comentarios útiles de los dictaminadores de este texto. Entre la primera entrega de esta contribución (24 de mayo de 2009) y su publicación, salió a la luz otro estudio del mismo documento por Hugo Ruiz Ortiz y Maarten Jansen intitulado El Lienzo de Otla. Memoria de un Paisaje Sagrado (Gobierno de Oaxaca \& Yuu Nuu, A.C., 2009).

${ }^{1}$ Véase Terraciano (2001) para una descripción detallada del yuhuitayu. En este texto uso las 
Éstos eran pequeños reinos gobernados por una pareja de gobernantes hereditarios. Ambos cónyuges necesitaban ser de linaje gobernante, y ambos conservaban sus respectivos títulos por separado para pasarlos, según previo acuerdo, a sus hijos. Las reglas que dictaban la selección de las parejas y el paso de los títulos eran parte de un gran sistema de relaciones interyuhuitayu basado en el mutuo reconocimiento de símbolos, prácticas (costumbres) y narrativas históricas, y cuyos orígenes deben buscarse en el inicio el periodo llamado "posclásico" por los arqueólogos, a mediados del siglo $x$. Ésta era una época de grandes cambios en que se gestaron las raíces de un nuevo orden socio político. Personajes como el guerrero 8 Venado pusieron -mediante su singular trayectoria y sus alianzas con otra áreas como Cholula-el fundamento de este orden. ${ }^{2}$ Importantes centros de la época epiclásica, como Cerro Jazmín, cedieron su lugar a los nuevos centros políticos del posclásico. En la Mixteca, Tututepec y Tilantongo surgieron como capitales del nuevo paisaje político. Durante el siglo XII, nuevos yuhuitayu como Tlaxiaco y Achiutla -ambos surgidos con base en importantes centros religiosos-, se formaron 0 se asociaron a esta gran red de relaciones. Así, progresivamente, los yuhuitayu llegaron a cubrir todo el paisaje mixteco.

Un área de desarrollo temprano de los yuhuitayu era el valle de Coixtlahuaca (mapa 1). Mientras su desarrollo como sistema político corrió paralelamente a lo ocurrido en la Mixteca, la región siempre se mantuvo algo apartada. Esto se debía a su particular narrativa histórica, que la diferenciaba de aquella de la Mixteca. Los gobernantes de esta área no trazaron sus orígenes en los árboles de Apoala u otros símbolos mixtecos, sino conservaron la memoria de un origen distinto. ${ }^{3}$ Además, reconocieron a sus propios héroes fundadores, entre ellos el famoso Atonaltzin, que dieron legitimidad a los linajes locales. ${ }^{4}$ Sin embargo, debido a

palabras mixtecas para las unidades sociopolíticas, principalmente por ser éstas más conocidas.

${ }^{2}$ Véase los trabajos de Byland y Pohl (1994) y Jansen y Pérez Jiménez (2007) para los rasgos generales de este proceso en la Mixteca.

${ }^{3}$ Por su complejidad, la discusión de estos lugares queda fuera del objetivo de este artículo. Me remito al estudio de Parmenter (1982, 38-44) y Doesburg y van Buren (1997, 111, 149-152) para una somera descripción y la tesis de Rincón Mautner (1999, 286-311). Actualmente, estoy trabajando en un texto sobre el tema.

${ }^{4}$ La versión más conocida de la historia de Atonaltzin proviene de la obra de fray 


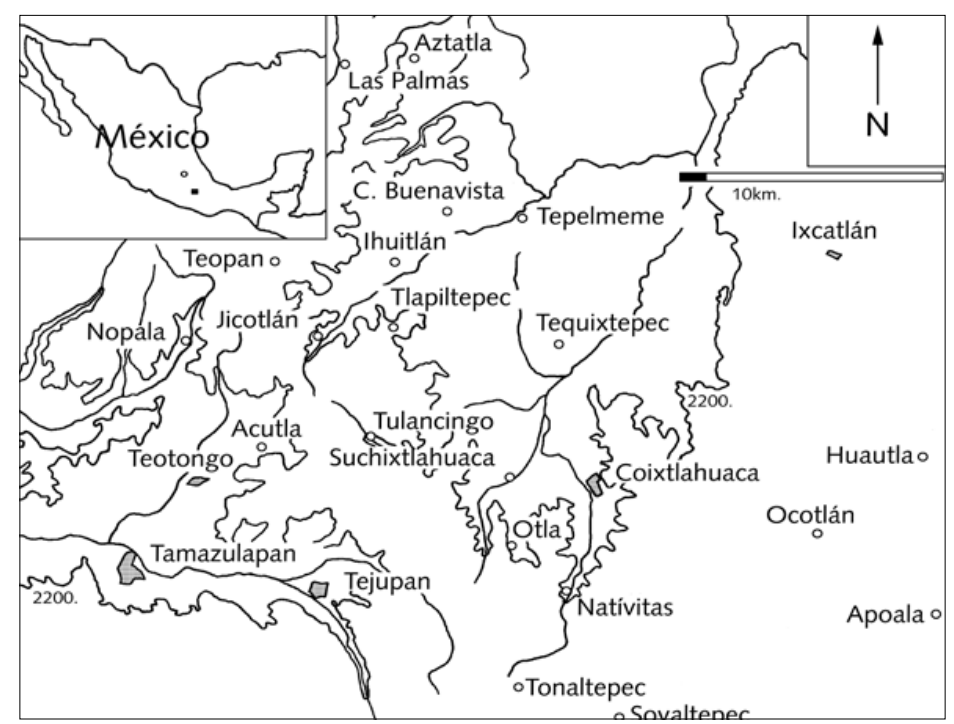

MAPA 1: La región ngiwa-chochona.

la cercanía entre las dos regiones, las dos narrativas se nutrieron de los mismos procesos regionales que moldearon el posclásico. ${ }^{5}$ Esta memoria está plasmada en numerosos documentos que nos permiten estudiar el desarrollo del sistema político del área de Coixtlahuaca desde el siglo XI hasta 1560 aproximadamente. Ya que estos documentos provienen de yuhuitayu que participaron en el mismo sistema político, su información se traslapa con la de los otros documentos de la misma región. Los documen-

Diego Durán (1984, 185-195). Los Anales de Cuauhtitlán (Anónimo 1975, pár. 67, 189 y 238) contienen datos adicionales importantes. Los documentos pictográficos de Coixtlahuaca confirman la existencia de Atonaltzin y lo llaman 6 Agua (véase van Doesburg y van Buren 1997, 107-110). Jansen (1982, 419) ya identificó a 7 Agua, el ancestro fundador de 6 Agua, como el primer Atonaltzin de la época de los toltecas.

${ }^{5}$ Por ejemplo, sobre todo durante el periodo entre 1050 y 1150 d.C. las dos tradiciones cuentan de contactos interregionales con el área de Cholula, los cuales servían para dar un importante respaldo religioso-ideológico a los primeros gobernantes posclásicos. Estos contactos quedaron truncados después de la conquista de Cholula por los teochichimecas en la segunda mitad del siglo XII. 
tos mencionan los mismos lugares, personajes históricos, acontecimientos y fechas, aunque cada vez en composiciones propias y variadas, de acuerdo con los objetivos de cada patrono. ${ }^{6}$ El Lienzo de Otla es uno de ellos.

Por lo anterior, resulta obvio que no podemos estudiar estos documentos de manera aislada, sino que éstos deben ser vistos como un conjunto y como expresiones de una sola "narrativa maestra"7 compartida por los yuhuitayu participantes en el sistema. Para estudiar e interpretar el Lienzo de Otla es necesario compararla con los otros documentos de la misma región e identificar su posición en esta "narrativa maestra". Además, es indispensable comparar la información contenida en el lienzo con los documentos guardados en los distintos archivos. Mediante este ejercicio será posible reconstruir el contexto en que se creó el lienzo y aventurarnos a identificar su mensaje general.

\section{El Grupo de Coixtlahuaca y el Lienzo de Otla}

El Lienzo de Otla es un miembro del llamado Grupo de Coixtlahuaca, un grupo de documentos interrelacionados provenientes del área bajo el

${ }^{6}$ Alfonso Caso $(1954,1958,1961)$ escribió los primeros comentarios al Fragmento Gómez de Orozco, el Códice Baranda y los lienzos de Tlapiltepec e Ihuitlán. Ross Parmenter $(1961,1970,1982,1993,1994,1997)$ añadió ideas adicionales, descubrió más documentos (los lienzos de Tequixtepec y el Lienzo de Tulancingo) y avanzó notoriamente en la identificación de lugares y la historia reciente de los documentos. Mary Elizabeth Smith (1973) y Caso (1979) dieron descripciones generales del contenido de estos documentos. Viola König (1986) y sus colegas de Hamburg analizaron el Lienzo de Coixtlahuaca II en detalle (véase también König 1999). Otros trabajos son de Johnson $(1994,1997)$ y Rincón Mautner (1994, 1995, 1996, 2000). Véase también van Doesburg 1998a, 1998b, 2000, 2001, 2002 y 2003 y van Doesburg y van Buren 1997.

${ }^{7}$ Con el término "narrativa maestra" me refiero a la idea de una narración global que da orden al registro histórico (aunque no necesariamente en el sentido postmodernista de Jean-François Lyotard). Esta gran historia se caracteriza por elementos de autoridad y referencias al desarrollo de los linajes gobernantes. Por lo mismo, unifica el mundo vivido y justifica las estructuras de poder. Similar a lo que ocurre con las metanarrativas en otras culturas, la "narrativa maestra" aquí tratada es una trama nunca contada en su totalidad, aunque múltiples narrativas más específicas y con objetivos particulares la reflejan y reafirman (véanse también Stephens y McCallum 1998). La comparación entre documentos deja entrever la estructura de esta narrativa. 
control del gran centro urbano de Coixtlahuaca. Hasta hace poco, la existencia del documento fue un secreto conservado celosamente por los habitantes de la pequeña comunidad. Sin embargo, desde hace años circulaban ya noticias de la existencia del documento en la región. El autor de este texto intentó ver el documento en el año de 2000, pero la propuesta no tuvo aceptación en la asamblea que se había convocado con este fin. En 2007, Carlos Rincón dio la noticia "oficial" de la existencia de este documento en un artículo publicado en el Latin American Indian Literatures Journal. Para escribir el artículo, Rincón se basó en ocho fotografías de detalles obtenidas del Delegado Local de la Procuraduría Agraria de Huajuapan. Por representar éstas una información incompleta y fragmentaria, la interpretación de glosas y glifos por parte de Rincón padece de varios errores, ${ }^{8}$ aunque en términos generales coincido con su interpretación. En abril de 2008 recibimos el permiso de fotografiar y estudiar brevemente el documento en la comunidad. En este artículo incluyo una fotografía completa del documento (figura 1) y una descripción de su contenido.

En total se conocen actualmente trece documentos del Grupo de Coixtlahuaca. ${ }^{9}$ Este conjunto de documentos es uno de los cuerpos literarios-históricos más importantes de la tradición literaria indígena de Mesoamérica, tanto por la belleza de las pinturas, como por la profundidad del registro histórico y la complejidad de los textos. Curiosamente, los documentos cubren una región relativamente pequeña. Aunque existen en algunos documentos referencias a relaciones políticas y genealógicas con el área de Yanhuitlán y con lo que hoy sería el sur del es-

\footnotetext{
${ }^{8}$ Notamos aquí la lectura de la glosa de la señora 5 Movimiento (olitzisoch) como olitziyoctla, de la señora 1 Lluvia (quiavsochi) como quiaviso Ani, del lugar glosado como tlaqualtogo como tlaqualcoya, y la identificación de la iglesia de Otla como la iglesia de Coixtlahuaca.

${ }^{9}$ Éstos son: Lienzo de Coixtlahuaca (México), Lienzo de Coixtlahuaca II o Seler II (Berlín), Lienzo A (Nueva Orleans), Lienzo de Ihuitlán (Brooklyn), Lienzo de Tulancingo (Tulancingo), Lienzo de Tlapiltepec (Toronto), Lienzo de Tequixtepec I, Lienzo de Tequixtepec II (ambos en Tequixtepec), Lienzo de Nativitas (Nativitas), Lienzo de Otla (Otla), Fragmento Gómez de Orozco (colección privada), Selden Roll (Oxford) y Codex Baranda (México). Hay otros documentos pictográficos de la región, como el Recibo de San Miguel Tequixtepec (Doesburg 2006), el Lienzo de Aztatla (Rincón 1999) y la Genealogía de Tequixtepec (Doesburg 2002), pero éstos no tienen conexiones con el grupo mencionado.
} 


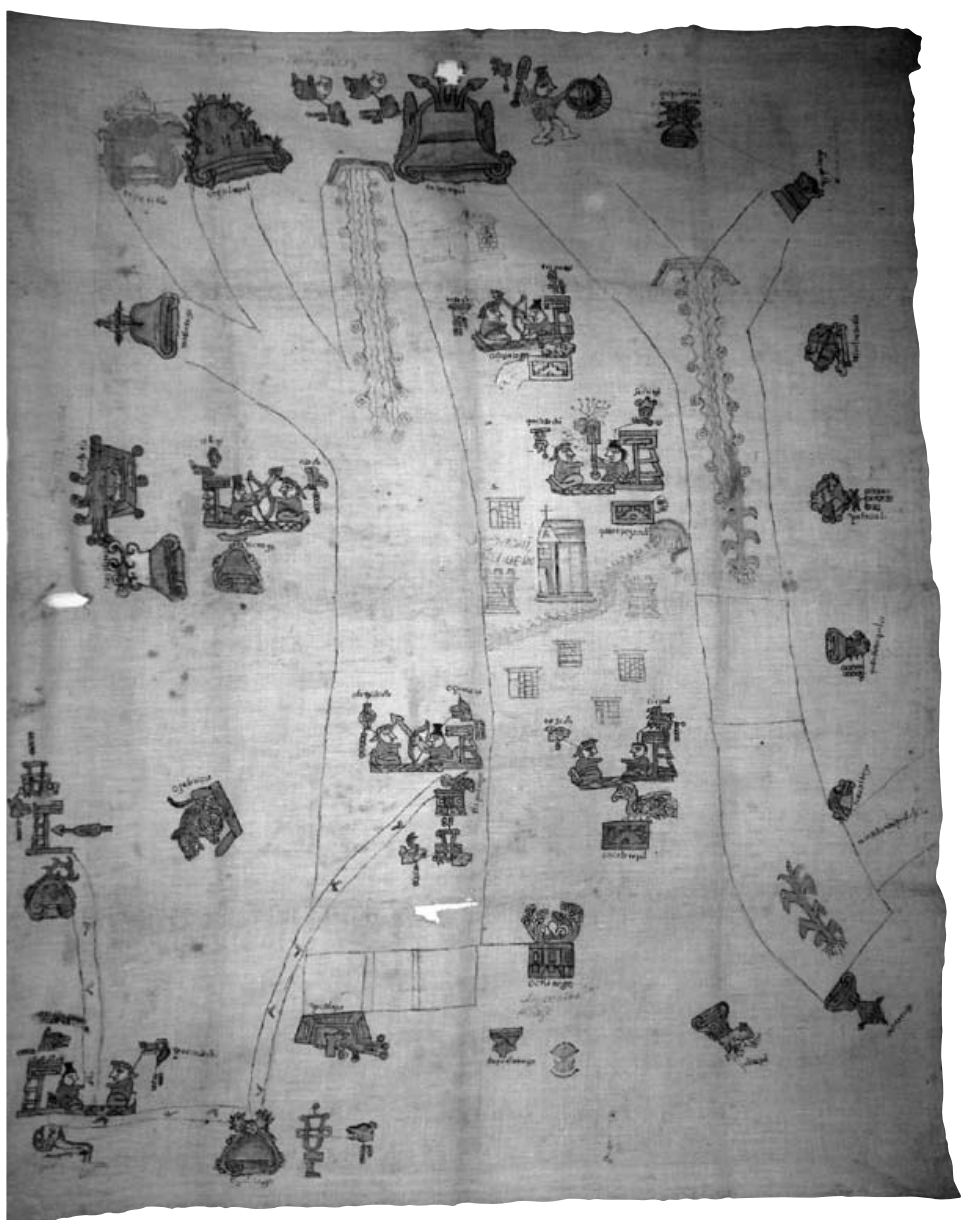

Figura 1. Lienzo de San Jerónimo Otla (fotografía y dibujo del autor).

tado de Puebla, el enfoque de la narrativa concierne el desarrollo de los yahuitayu en el valle de Coixtlahuaca. La razón para esta proliferación de documentos en el valle de Coixtlahuaca es una incógnita.

Con el tiempo, muchos de los documentos del grupo salieron de la región. Como objetos apreciados por coleccionistas de todas las épocas, 


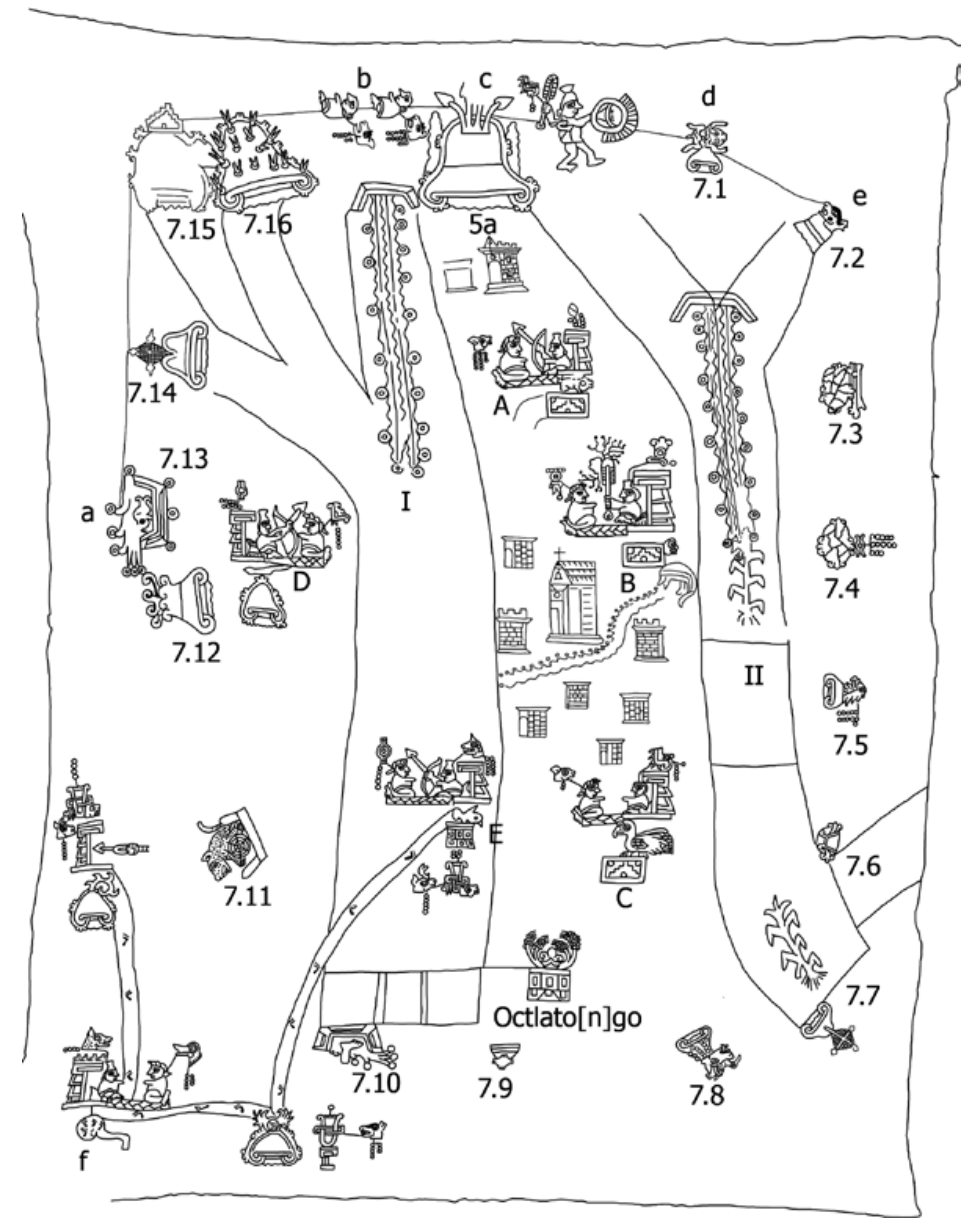

fueron robados y comprados. Un documento, el Códice Baranda, salió de la región tan temprano como en la primera mitad del siglo XVIII, cuando llegó a la colección del caballero Lorenzo Boturini Benaducci (17021751). Otros salieron en los últimos años del siglo xIx (el Lienzo de Coixtlahuaca II) o en los primeros del siglo xx (el Lienzo de Tlapiltepec y el Lienzo 
de Ihuitlán). El último en salir fue el Lienzo de Coixtlahuaca, en 1941. Hoy existen documentos en los Estados Unidos, en Canadá, en Alemania, en Inglaterra y en la ciudad de México. Sólo cinco se conservan en el área de Coixtlahuaca actualmente. Debido a esta desconexión de sus lugares de origen no siempre es fácil saber de qué comunidad provienen los documentos en los museos. Sin embargo, es posible confirmar los lugares de origen de diez de los documentos: Coixtlahuaca tenía 4 lienzos, ${ }^{10}$ Ihuitlán tenía 2 lienzos, ${ }_{1}^{11}$ Tequixtepec tiene 2 lienzos, Nativitas tiene un lienzo y Otla otro más. Hay tres documentos más sin procedencia precisa: los llamados Rollo Selden (Oxford), Códice Baranda (México) y Fragmento Gómez de Orozco (colección privada).

La distribución de los documentos refleja de alguna manera la jerarquía política en el valle. Coixtlahuaca era desde el inicio del posclásico tardío un formidable centro urbano que logró dominar todas las demás comunidades en la región. ${ }^{12}$ Como centro comercial en la ruta entre el centro de México y las costas tropicales de Guatemala captaba un caudal importante de impuestos. Su importancia económica era tal que a mediados del siglo XV atrajo la atención de los gobernantes de la Triple Alianza, por lo que se dispusieron a conquistarlo. ${ }^{13}$ El embate mexica duró cuatro años, de 1458 a 1462, hasta que la ciudad cayó y su heroico gobernante Atonaltzin murió. Aunque esta historia es bien conocida y parte del saber popular, menos conocida es la larga trayectoria de este macroyuhuitayu que heredó Atonaltzin de su padre 10 Serpiente. Precisamente esta historia es la que contienen los documentos del Grupo de Coixtlahuaca. Ahora, esta historia es registrada en dos distintos niveles.

\footnotetext{
${ }^{10}$ De estos cuatro, uno está en el Museo Nacional de Antropología, otro en el Museo Etnográfico de Berlín (Alemania), otro-llamado el Lienzo de Tlapiltepec-en el Museo Real de Ontario de Toronto (Canadá). El cuarto lienzo está perdido y sólo se conoce a través de una copia llamada Lienzo A en la Universidad de Tulane en Nueva Orleans.

${ }^{11}$ De estos dos, uno está en el Museo de Brooklyn, Nueva York y el otro en San Miguel Tulancingo.

${ }^{12}$ Actualmente, Stephen Kowalewski dirige un importante proyecto de recorridos arqueológicos en la región. Véase el sitio del proyecto en http: / / hatch.anthro.uga.edu/ coixtlahuaca2008/

${ }^{13}$ También es posible que la incursión mexica se debió a una alianza entre los mexica y algunos señoríos mixtecos, como Tlaxiaco, que vieron en la rápida expansión política de Atonaltzin una señal peligrosa.
} 
Por su posición como "capital" política de la región, los cuatro lienzos de Coixtlahuaca tratan asuntos de alcance regional amplio y abarcan un área geográfica muy grande: el Lienzo de Tlapiltepec y el Lienzo de Coixtlahuaca II nos proveen de una visión amplia de la historia de los yuhuitayu en la región de Coixtlahuaca desde el siglo XI hasta el Xvi; los otros dos lienzos registran la creación de un macroyuhuitayu, que iba desde Cerro Verde en el sur hasta el río Calapa en el norte, en las primeras décadas del siglo XVI, mediante la fijación de linderos. ${ }^{14}$ Los demás documentos tratan más bien de las consecuencias de los procesos regionales sobre el desarrollo local. Representan los intereses locales de los pequeños yuhuitayu integrados en el "sistema Coixtlahuaca". El Lienzo de Otla es un buen ejemplo de un documento de este último grupo.

\section{La eStructura política de los yuhuitayu DE CoIXTLAHUACA}

Aunque Coixtlahuaca era la "capital" de la región, es importante entender que no siempre había un solo linaje gobernante, ni había un solo centro urbano en Coixtlahuaca. Más bien, eran varios linajes gobernantes (yuhuitayu) los que juntos conformaban el gobierno de Coixtlahuaca. Cada uno tenía una sede o "barrio" específico donde estaba su palacio (añiñe en mixteco y $n d u c ̧ e$ en chochona). Estas sedes con sus edificios administrativos y religiosos asociados estaban cerca una de la otra, por lo que daba la impresión de formar un centro urbano. Con el paso del tiempo, de estos yuhuitayu se desprendieron nuevos yuhuitayu. Así, el linaje del famoso Atonaltzin estaba emparentado directamente con los gobernantes de Ihuitlán y de Tequixtepec y, como veremos más adelante, otro linaje estaba relacionado con los yuhuitayu en Nativitas y Otla, o sea la parte sur del valle. Desde sus palacios ubicados en estos lugares, los gobernantes principales delegaron el gobierno a los nobles, que eran en muchos casos sus parientes. Cada noble estaba a cargo de una cierta cantidad de tierras y campesinos. Los campesinos no vivían en un solo pueblo, como es el caso hoy, sino vivían en "barrios" (siqui o siña en mixteco y sindi en chochona) dispersos por los campos, cerca de sus te-

\footnotetext{
${ }^{14}$ Doesburg 2003, 79-81.
} 
rrenos. De hecho, es posible que en un principio los nobles eran los responsables (por encargo del gobernante) de la colonización de los nichos productivos en la región y la construcción y el mantenimiento de los sistemas de terrazas en las barrancas. La familias campesinas que ejecutaron este trabajo se constituyeron en un siqui. Existe evidencia arqueológica que este proceso corresponde al incremento de la población durante el posclásico. ${ }^{15}$ Aparte de la colonización, la conquista de tierras y campesinos ya existentes en nichos vecinos era sin duda otro mecanismo mediante el cual los gobernantes y sus nobles se podían hacer de nuevos siqui. Por haber dirigido la colonización o la conquista, los nobles se consideraban los dueños (en un sentido residual) de las tierras del siqui, lo que se expresó mediante la construcción de un palacio del noble en el siqui y el pago de tributo y servicios por parte de los campesinos en compensación por el uso de la tierra: una parte de la producción agrícola se destinaba al sustento de las casas nobles y los campesinos y sus familias también dieron servicios de mantenimiento, abastecimiento y trabajos en la cocina. Por otro lado, los nobles representaban a la población de sus siqui en las juntas de gobierno en el yuhuitayu.

Después de la muerte de Atonaltzin en 1462, el gobierno de Coixtlahuaca quedó en manos de un segundo linaje, justificando su posición mediante un matrimonio con una supuesta hija de Atonaltzin. Es posible que esta situación generó el conflicto del que se aprovechó Cozcacuauhtli en la primera década del siglo xvı para hacerse del control del valle con la ayuda de los mexica. ${ }^{16}$

A raíz de la conquista, la organización sociopolítica de la Mixteca pasó por un acelerado proceso de cambio en que los yuhuitayu tuvieron que redefinir y reorganizarse. La epidemia de 1545 a 1548, las llamadas "congregaciones" y la fijación de los linderos de los yuhuitayu tuvieron un gran impacto. A mediados del siglo XVI, con la introducción del ayuntamiento como nueva forma de gobierno, la antigua organización perduró bajo los

\footnotetext{
${ }^{15}$ En 1969 y 1972, Ronald Spores notó el incremento en la construcción de las terrazas tipo "lama-bordo" durante la fase Nativitas (coincidiendo con el posclásico) e interpretó este fenómeno como "un mecanismo dirigido al incremento de la producción agrícola en respuesta a las necesidades crecientes de una población en aumento" $(1972,189)$.

${ }^{16}$ La historia de Cozcacuauhtli (11 Zopilote en los lienzos) es conocido por la versión que nos dejó Torquemada, Libro II, cap. 75 (1986, 207-209).
} 
nombres españoles: los gobernantes tomaron control del puesto de gobernador, gobernantes de linajes secundarios fungían como alcaldes y los nobles de los siqui se convirtieron en los regidores del cabildo. En Coixtlahuaca, el linaje gobernante mantuvo un control de los puestos principales en el ayuntamiento hasta 1574. A partir de este momento entró en vigor un tipo de rotación entre los principales nobles de la región. ${ }^{17}$

En el caso de Otla, este fue considerado durante el siglo XVI como una "barrio" de San Cristóbal, a su vez un sujeto de Coixtlahuaca. Sin embargo, a finales del siglo XVII, varios sujetos de Coixtlahuaca -principalmente los que ya contaban con una iglesia propia- buscaron independizarse políticamente, solicitando el derecho de elegir su propio cabildo. ${ }^{18}$ También San Jerónimo Otla participó en este proceso, pero el intento no fructificó. Curiosamente, hubo una discusión sobre si Otla pertenecía a Coixtlahuaca o a San Cristóbal. Hoy en día, San Jerónimo Otla es una agencia de San Juan Bautista Coixtlahuaca.

\section{El SISTEMA GRÁFICO EMPLEADO EN EL LIENZO DE OTLA}

En la época posclásica, los escribanos de los yuhuitayu desarrollaron un sistema gráfico muy particular para registrar la historia de los linajes gobernantes, ciertos aspectos de la religión y datos relacionados con el

\footnotetext{
${ }^{17}$ Doesburg 2003, 74-75.

${ }^{18}$ Hasta la segunda mitad del siglo XVII, los pueblos sujetos a Coixtlahuaca estaban representados en el cabildo mediante un regidor. Aunque inicialmente eran sólo unos cuantos regidores, representando los asentamientos principales, a mediados del siglo XVII, todos los pueblos (también los sujetos de los sujetos) tenían ya su representante. Entre 1678 y 1681 varios pueblos trataron de separarse de la cabecera de Coixtlahuaca y eligir sus propias autoridades (también Mendoza 2004, 46-49). Sin embargo, no recibieron el permiso necesario (Archivo General de la Nación, Indios, vol. 25, exp. 360 (1678) y 484 (1679) y vol. 26, exp. 20 (1680) y 32 (1681)). Sólo se logró que se insistiera sobre la alternancia entre los pueblos en la elección de los oficiales de república (gobernador y alcaldes). Finalmente, en 1706, San Cristóbal y San Jerónimo lograron una licencia para eligir dos alcaldes y cuatro regidores cada uno (Archivo General de la Nación, Indios, vol. 37, exp. 85 (1708) y vol. 44, exp. 56 (1720) y 127 (1721)), aunque quedaron sujetos a la cabecera y al mando de su gobernador. En 1718, otras comunidades en la parte noroeste del valle, representadas por Ihuitlán, intentaron lo mismo y lograron licencia para eligir alcaldes y regidores (Archivo General de la Nación, Indios, vol. 42, exp. 9, 10 y 126, 127 y 128 y 140).
} 


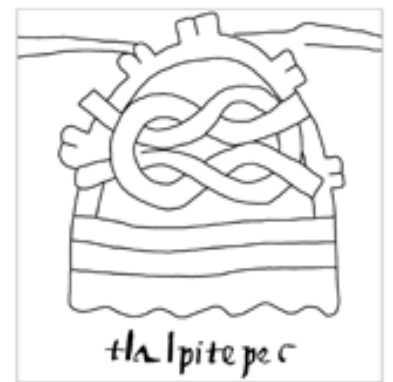

FIGURA 2. El topograma de Tlapiltepec (Lienzo de Tequixtepec I).

tributo y la población. Este sistema usado en la Mixteca y en el área de Coixtlahuaca es llamado "pictografía" o "semasiografía". En este sistema los signos o glifos no se estructuran y agrupan según la estructura gramatical de la lengua (como es el caso con la escritura latina), sino conforman composiciones ("escenas") que tienen referentes directos en el mundo real, aunque de manera muy estilizada.

Para "leer" esta escritura comenzamos por la identificación de los signos o glifos individuales. La gran mayoría de los glifos representa -de manera estilizada, pero reconocible- un objeto del mundo real o sobrenatural. En la figura 2 se da un ejemplo de un documento de San Miguel Tequixtepec: la imagen consiste en dos glifos sobrepuestos, uno que representa un cerro y otro que representa un nudo. La lectura es "cerro del nudo". Conocemos el significado de la mayoría de los signos individuales gracias al análisis riguroso y la comparación meticulosa entre documentos que tienen glosas, o sea palabras en la escritura latina añadida durante las primeras décadas de la época colonial, al lado de la pictografía. En el caso de la figura 2, el glosista añadió tlalpi[l]tepec ("en el cerro del nudo" en nahuatl, de tlalpil[li], "nudo" y tepec, "en el cerro") abajo de la imagen. De hecho, la imagen representa el pueblo conocido actualmente como San Mateo Tlapiltepec. Estos topogramas o signos para representar lugares (pueblos, linderos, sitios sagrados, etcétera) son muy comunes en los textos pictográficos.

El uso de la lengua náhuatl para escribir las glosas era común en los primeros años de la época colonial: aparte de servir como una "lingua 


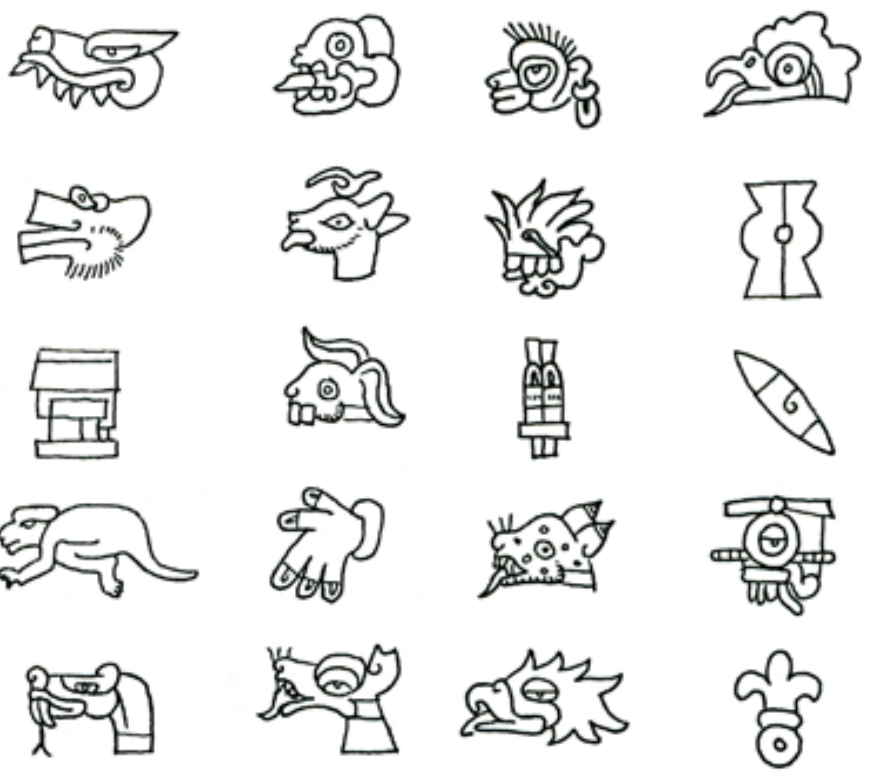

FiguRA 3. Los 20 nombres de los días del ciclo de 260 días.

franca" en partes de Mesoamérica también fue la primera en contar con una tradición escrita en letras latinas. Este fenómeno se nota además en otros lienzos (p.e. el Lienzo de Ihuitlán) y así también en el Lienzo de Otla. ${ }^{19}$

La "lectura" del texto se realiza mediante la interpretación de las relaciones que los signos e imágenes compuestos guardan entre sí. Como dijimos, estas relaciones no son lingüísticas, sino reflejan de manera estilizada las relaciones en el mundo real. Un hombre y una mujer sentados sobre un petate representan primero a una pareja de casados (de otro modo no se sentarían hombre y mujer sobre un mismo petate) y

${ }^{19}$ De hecho, la proliferación de topónimos en lengua náhuatl en la Mixteca se debe probablemente más al trabajo de los primeros intérpretes (siempre usando el náhuatl como lengua intermedia entre el español y la lengua local) que a la dominación por la Triple Alianza. 
más específico a los gobernantes de un yuhuitayu. Si este petate está frente a una edificación, esta última representa el palacio del linaje, donde se conservaban los objetos sagrados relacionados con el linaje, como el envoltorio sagrado. Si la pareja está sentada encima de un topograma, éste representa la comunidad donde está el yuhuitayu. Ahora, para identificar a las personas se pintaron sus nombres cerca de la cabeza. Obviamente, en la época prehispánica aun no se usaban los nombres de los evangelistas, apóstoles y santos o reyes importados de España. Para nombrar a una persona, se usaba el nombre del día en que esta persona había nacido. Los nombres de los días se formaban por la intersección de dos ciclos de distinta duración: uno menor de trece números (de 1 al 13) y otro de veinte entidades (de Lagarto a Flor). Estos números y entidades están representados en la figura 3. Combinándose estos dos ciclos, se obtienen $260(13 \times 20)$ combinaciones distintas que conforman los nombres de los días. Un buen ejemplo de este tipo de nombre es el del guerrero-rey mixteco 8 Venado. En las lenguas mixteca y chochona se solían dar los nombres completos, incluyendo número y entidad, pero en la lengua náhuatl era común no representar los numerales. Además, a los nombres de los hombres se añadía el sufijo reverencial-tzin y a los nombres de las mujeres el sufijo -xoch (de xochitl, "flor"). De esta manera, el nombre 6 Agua en mixteco corresponde a Atonaltzin ("el venerable con el nombre Agua") en náhuatl.

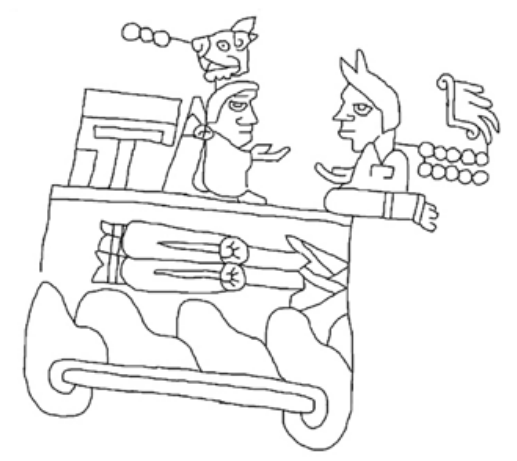

FigURA 4. Los gobernantes señor 3 Ocelote y señora 10 Agua en "Cerro de Flechas" (Lienzo de Coixtlahuaca II). 
En el ejemplo presentado en la figura 4 vemos el topograma para "cerro de las flechas". Encima está una pareja de gobernantes y su palacio, la sede del yuhuitayu. Por lo anterior, la "lectura" de la escena podría ser: "en el cerro de las flechas gobernó la pareja real formada por el señor 3 Jaguar y la señora 10 Agua".

Finalmente, es de notar que las composiciones de los textos toman formas distintas según el formato en que se plasmaron: en un libro (códice) hecho de una tira de piel o papel, las escenas están ordenadas de tal forma que la secuencia de las escenas sigue el desarrollo del tiempo. El formato de lienzo era más apropiado para una composición cartográfica en que las escenas estaban colocadas siguiendo la distribución de eventos en la geografía local. La mayoría de los textos del valle de Coixtlahuaca son lienzos y revelan -por lo mismo- una composición cartográfica; así también el Lienzo de Otla.

\section{El LIENZO DE OtLA COMO MAPA}

La distribución espacial de topogramas sobre el lienzo sugiere a primera vista una composición cartográfica. El lienzo es en realidad un mapa esquemático del territorio de Otla. Comencemos la "lectura" de este mapa con un topograma conocido: el que representa al gran Cerro Verde en el sur del valle de Coixtlahuaca (figura $5 \mathrm{a}^{20}$ ). El topograma de este cerro, a cuyo pies está el actual pueblo de Otla, aparece también en otros lienzos del valle, como el Lienzo de Tlapiltepec y el Lienzo de Nativitas (figuras 5b y 5c). Se le representa como un cerro con algunas hojas verdes en su cima. En el Lienzo de Nativitas va acompañado por la glosa yucucuy ("cerro verde" en mixteco). ${ }^{21}$ En el Lienzo de Otla el topograma tiene dos elementos verdes adicionales en sus laderas. Una glosa dice sosoctepel (o xoxoctepetl en la lengua nahuatl), "cerro verde" (xoxoctic, xoxouhqui-"cosa verde"). ${ }^{22}$

\footnotetext{
${ }^{20}$ Las referencias a detalles en el lienzo que tienen números o letras en el texto, se ubican en el dibujo del lienzo incluido en este artículo mediante los mismos números y letras.

${ }^{21}$ Caso 1961, 259-60; Parmenter 1997, 279. Las glosas que acompañan los linderos en el Lienzo de Nativitas fueron añadidas posteriormente y no pertenecen al estrato original del lienzo (Doesburg 2001,35-37).

${ }^{22}$ En el siglo XVI, la letra $<\mathrm{s}>$ representaba un sonido similar al [sh] del actual inglés. Este sonido se representó también mediante $l a<x>$.
} 


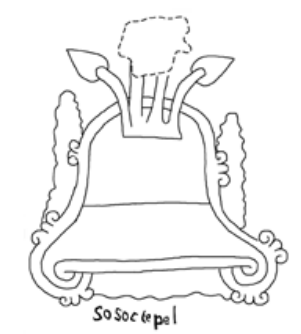

Figura 5a. Sosoctepel, el Cerro Verde (Lienzo de Otla).

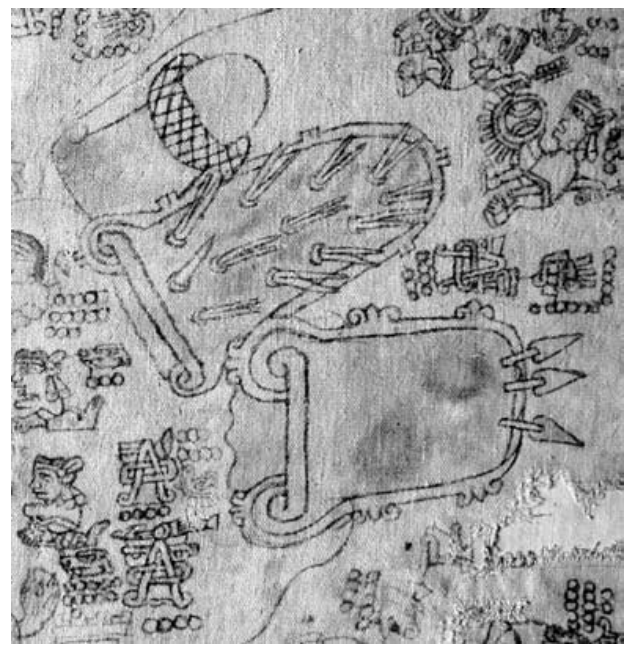

Figura 5b. El Cerro Verde y el Nudo Mixteco (Lienzo de Tlapiltepec). Cortesía del Museo Real de Ontario, Canadá (@ ROM).

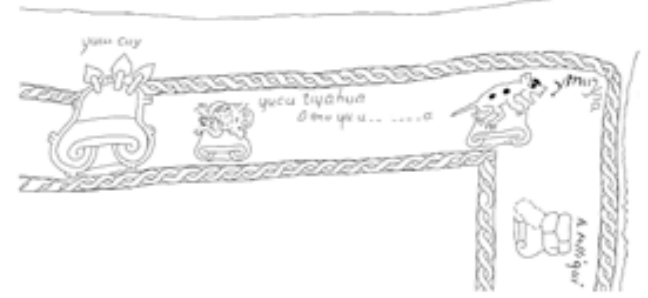

FIGURa 5c. Yucucuy, el Cerro Verde (Lienzo de Nativitas). 


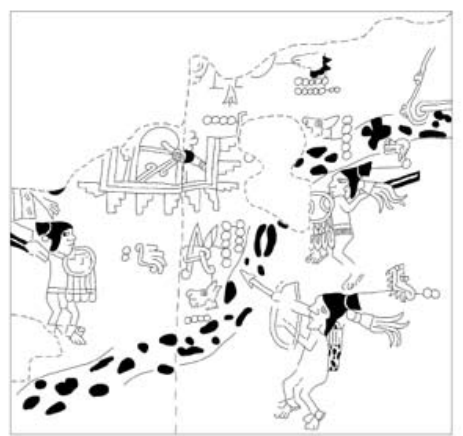

FigURA 6a. El guerrero 2 Lagarto cerca de Cerro Verde en el Lienzo de Coixtlahuaca II.

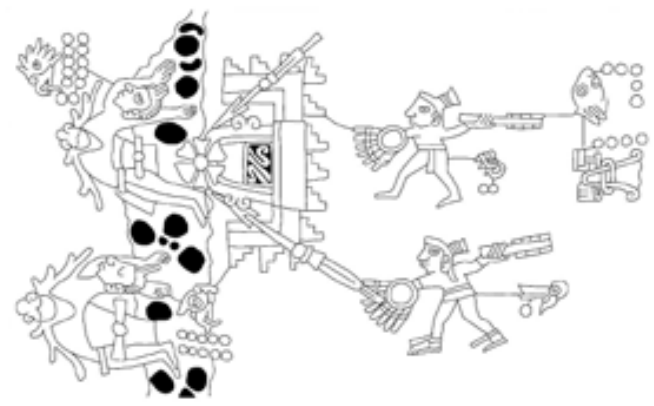

Figura 6b. El guerrero 2 Lagarto cerca de Cerro Verde en el Lienzo de Coixtlahuaca.

Por lo anterior, este lado del lienzo representa el sur del área. A su lado aparece un guerrero llamado 2 Lagarto, con escudo y macana. No sé quién fue 2 Lagarto, pero también aparece en otros documentos del valle, junto con un guerrero 1 Viento, conquistando por el rumbo de Cerro Verde (figuras 6a y b). Aquí el pintor seguramente hace alusión a una tradición oral que hoy desconocemos pero que posiblemente justificó históricamente el dominio de Coixtlahuaca sobre el área del Cerro Verde. ${ }^{23}$ No

\footnotetext{
${ }^{23}$ De la misma manera, múltiples pequeñas conquistas dibujadas en los márgenes del Lienzo de Coixtlahuaca (donde se pintaron los linderos) parecen justificar los reclamos territoriales de Coixtlahuaca.
} 
he podido identificar a los dos hombres (7 Perro y 13 ¿Ocelote?) sentados al otro lado del topograma de Cerro Verde.

Cerro Verde es parte de una serie de topogramas que representan los linderos de Otla. Todos están orientados con su base hacia el interior del círculo que forman y todos llevan glosas en la lengua náhuatl. Algunos están conectados por una tenue línea roja. Muchos de los nombres de linderos registrados aquí se perdieron con el tiempo o fueron sustituidos por otros, a veces en la lengua española, por lo que su identificación en la actualidad no es evidente. Comenzando con el glifo inmediatamente al lado poniente de Cerro Verde, los linderos son (figura 7):

1. -queyaltepel (cueyaltepetl): "cerro de la rana" (cueyatl - "rana").

GLIFO: una rana encima de un cerro.

2. -yçquiltogo (itzcuintongo $\left.{ }^{24}\right)$, "en el pequeño lugar del perro" (ytzcuintli- "perro").

GLIFO: una cabeza de un perro encima de un cerro.

3. -tescalnepatla (texcalnepantla), "a la mitad del peñasco" (texcalli - "ris$\mathrm{co}^{\prime} /$ nepantla - "en medio").

GLIFO: dos huesos encima de una roca.

4. -yoliostol (yollioztotl), "la caverna del [señor] Ollin" (ollin - "movimiento" / oztotl - "caverna"25).

GLIFO: una roca con la fecha 13 Movimiento.

5. -quavctliitzaqualco (quauhtli itzaqualco), "en su altar del [señor] Aguila" (quauhtli - "águila" / tzaqualli-"altar, base piramidal").

GLIFO: el glifo de 11 Aguila encima de un cerro.

6. -tecasiltogo (tecaxitongo), "en el pequeño lugar del cajete de piedra" (tetl- "piedra", caxitl - "cajete").

GLIFO: una oquedad en forma de un cajete en una roca.

7. -matlatogo (matlatongo), "en el pequeño lugar de la red" (matlatl "red").

GLIFO: una red para pescar encima de un cerro.

8. -çulitepel (çoltepetl), "el cerro de la codorniz" (çolin - "codorniz").

\footnotetext{
${ }^{24}$ La curiosidad de no representar el sonido [n] después de un vocal ocurre también en el Lienzo de Tequixtepec I y el Lienzo de Ihuitlán y es una característica de la ortografía de mediados del siglo XVI.

${ }^{25}$ Es curioso el uso de la letra $<\mathrm{s}>$ aquí, ya que en las demás glosas ésta representa un sonido similar al [sh] del inglés.
} 


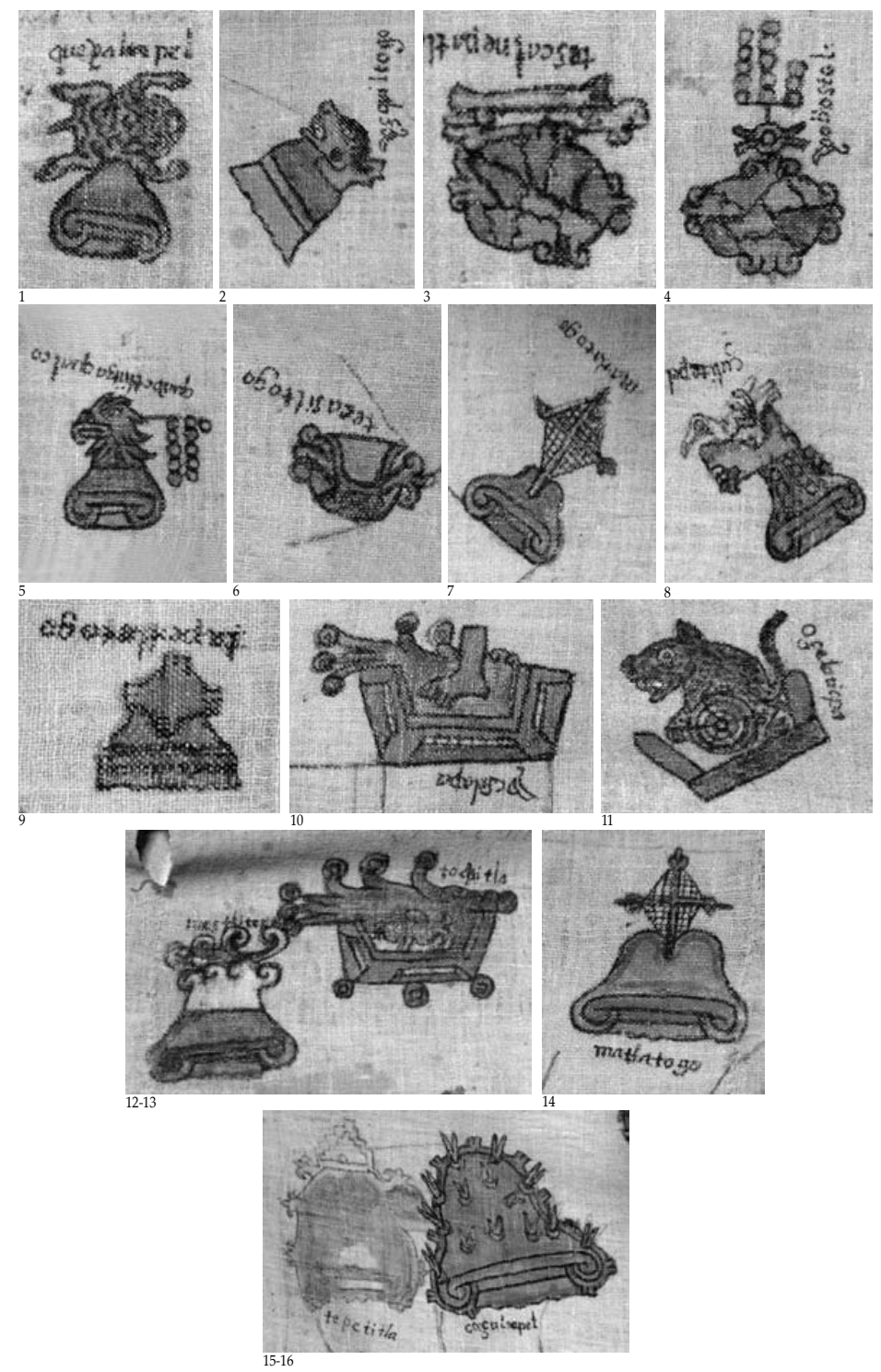

Figura 7. Los linderos en el Lienzo de Otla. 
GLIFO: una codorniz encima de la fecha 13 Venado colocada sobre un cerro.

9. -tepetlatogo (tepetlatongo), "en el pequeño lugar de tepetate".

GLIFO: una piedra (de tepetate) sobre un cerro.

10. -ycs(i)lapa (ycxilapa), "en el agua del pie" (ycxitl - "pie").

GLIFO: un pie en un cuerpo de agua (río).

11. -oçeloticpa (oçeloticpac), "encima del ocelote".

GLIFO: un ocelote sobre una telaraña (en mixteco yuhua es tanto "telaraña" como "barranca" y quizás aquí se quiere comunicar el segundo significado), ambos colocados en una forma que consiste en una base y dos elementos parados en sus extremos (¿una barranca?).

Este lindero coincide posiblemente con la actual Peña de León entre Otla y Nativitas y que fue la razón de un largo pleito entre Otla, Suchixtlahuaca y Coixtlahuaca (Rincón 2007).

12. -mestlite(pel) (mixtli tepetl), "cerro de la nube" (mixtli - "nube").

GLIFO: una nube encima de un cerro.

13. -tochitla (tochintla), "lugar de conejos" (tochin/tochtli - "conejo").

GLIFO: un pez (i?) en un cuerpo de agua (río).

14. -matlatogo (matlatongo), "en el pequeño lugar de la red" (matlatl "red").

GLIFO: una red para pescar encima de un cerro (véase el topograma 7). 15. -tepetitla (tepetitla), "lugar de cerros".

GLIFo: un "friso" (tablero tipo Mitla) parcial sobre un cerro. No puedo identificar el elemento anaranjado en el costado derecho del cerro. Este dibujo fue ejecutado en una línea más tenue que la de los demás dibujos y muestra diferencias estilísticas con los demás topogramas, por ejemplo en la forma de las protuberancias sobre la superficie del cerro. Por lo tanto pienso que puede ser un añadido a la composición original.

16. -coçultepel [...], "cerro de la cuna/ tórtola/ langostino" (cozolli "cuna"; cozohtli - "tórtola", cozolin - "langostino").

GLIFO: un cerro lleno de espinas.

Aunque en la mayoría de los casos hay una buena correspondencia entre glosa y glifo, observamos que en los números 3,13 y 16 hay curiosas discrepancias que necesitan una explicación más precisa. En el caso del número 3, el glifo consiste en dos huesos encima de una roca, aunque la glosa significa "a la mitad del peñasco". Una solución parcial a 
esta discrepancia entre glifo y glosa encontramos mediante la comparación con el Lienzo de Nativitas. Por alguna razón, el Lienzo de Nativitas marca entre los linderos de esta comunidad cuatro lugares que son idénticos a cuatro de los linderos en el Lienzo de Otla, creando de esta manera un cierto traslape entre los dos territorios (figura 5c). Esto llevó, por supuesto, a problemas durante mucho tiempo (más adelante ofrecemos una hipótesis del por qué de este traslape). Notemos que los cuatro linderos del Lienzo de Nativitas que se traslapan con los del Lienzo de Otla son: "cerro verde" (yucucuy); "cerro de la rana" (yucu tiyahua), lindero con Tejupan; "cerro del perro" (ytnuyna) y "peña del hueso" (totolliqui). Este último, que coincidiría con Texcalnepantla en la secuencia en el Lienzo de Otla, explica el glifo del número 3 en el Lienzo de Otla: aparentemente, el pintor dibujó el nombre mixteco en el topograma, pero puso un topónimo náhuatl al lado. No sabemos si Texcalnepantla es sencillamente el nombre náhuatl del lugar llamado Totoyeque en mixteco ${ }^{26} \mathrm{o} \mathrm{si}$ se trata de dos lugares distintos pero muy cercanos.

El conjunto de los glifos 15, 16 y Cerro Verde aparece también en una de las esquinas del Lienzo de Tlapiltepec (quizás originalmente procedente de Coixtlahuaca) y representa lo que se conoce como el Nudo Mixteco (figura 5b). Este sierra tiene actualmente cuatro cimas muy notables: Cerro Verde, Cerro Sotol, Cerro Paloma y Cerro Jazmín. Las últimas tres tienen importantes vestigios arqueológicos de la época clásica. De este conjunto de cerros bajan muchas cañadas, dos de las cuales están representadas en el Lienzo de Otla mediante líneas paralelas que atraviesan el documento: (I) del conjunto de Matlatongo, Cozoltepetl y el pie de Cerro Verde parten tres barrancas que se juntan en una sola que pasa de sur a norte. Es la cañada del río Piaña al oriente de Otla. Al pie del Cerro Verde está representado el manantial, donde nace un corriente de agua. El manantial aparece como una variante sencilla del recipiente de agua que normalmente representa a los cuerpos de agua (véase, por ejemplo, el topograma 10). Mediante una línea de color y grosor distinto a las de los bordes de las barrancas, el topograma 15, de posterior dibujo, fue ligado al conjunto de barrancas.

${ }^{26}$ Quizás el lindero estaba a la mitad de la "peña del hueso", por lo que se le conoció también como "a la mitad del peñasco". 


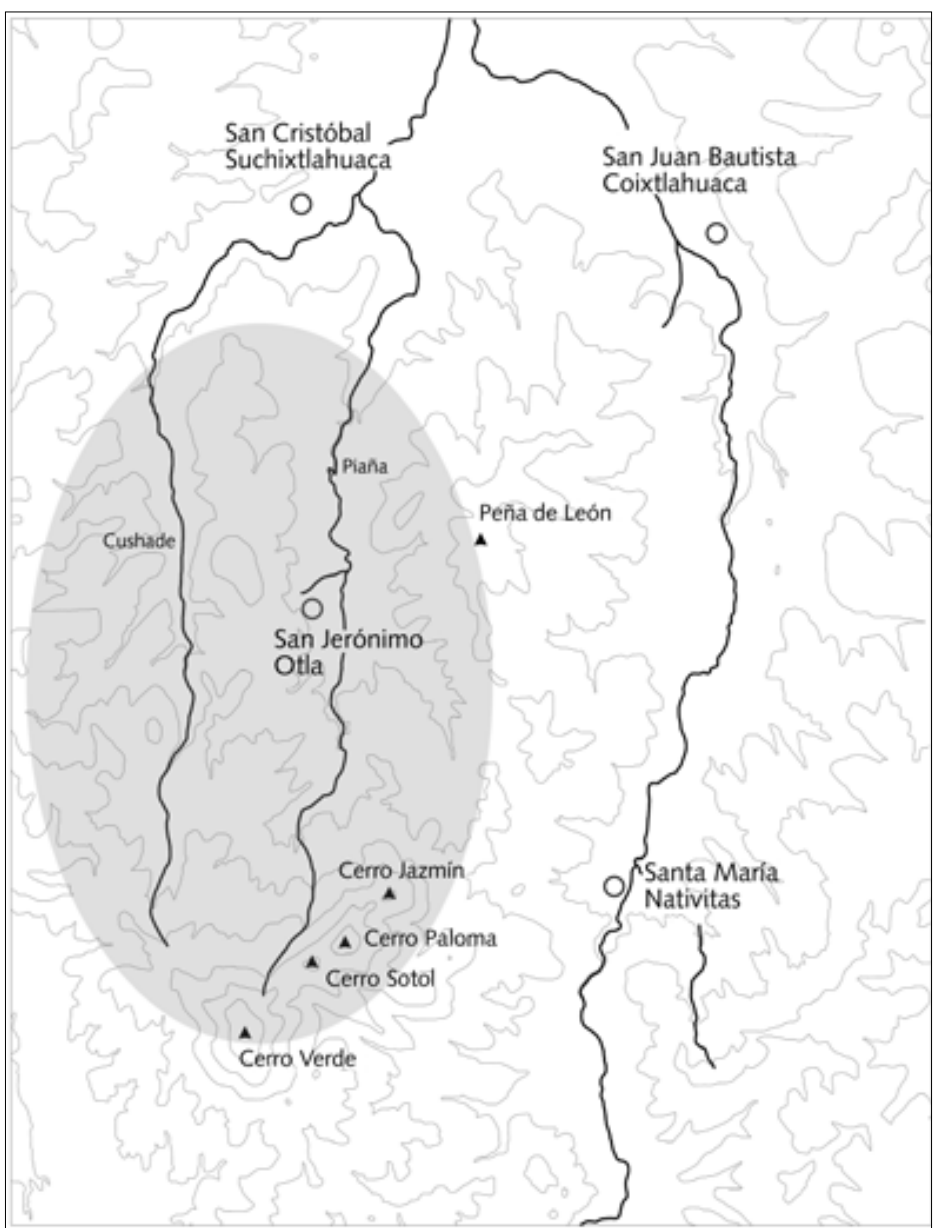

MAPA 2: La región de San Jerónimo Otla.

(II) del pie de Cerro Verde y de Itzcuintongo bajan otras dos barrancas, formando la cañada del río Cushade al poniente de Otla. En el punto de su confluencia está el manantial de donde emana la corriente de agua. En la cañada de Cushade se ven dos plantas de maíz y tres líneas transversales, lo que sugiere que se están indicando las terrazas grandes 
de tipo lama-bordo que bajan en esta cañada. En una cañada lateral, que se une con la Cushade después del lindero Tecaxitongo, se lee nica selioti(ca) ymil chila, "aquí está dividida su milpa [en] Chila". Chila era un barrio de Suchixtlahuaca en los límites con Otla (véase más abajo).

Esta estructura geográfica es inmediatamente evidente al observar el mapa de esta zona (mapa 2). Esta "lectura" geográfica tiene algunas consecuencias: en una publicación anterior sobre el Lienzo de Nativitas ${ }^{27}$ sostuve que el glifo 16 podría representar el Cerro Correoso de Nativitas, pero su ubicación en relación con las barrancas indica que debe corresponder a una de las cimas del Nudo Mixteco, el Sotol, Paloma o Jazmín. ${ }^{28}$ Llama la atención que una de las posibles traducciones de Cozoltepec es "cerro de la tórtola".

En algún momento posterior, alguien volvió a escribir los nombres de algunos linderos en los márgenes del documento, junto a algunos de los topogramas. Estos son: a) agua puerca (cerca de Tochitla); b) cerro berde chiquito (cerca de Xoxoctepetl); c) cerro berde grande (idem); d) cerro de rana (cerca de Cueyaltepetl); e) loma del perro (cerca del Ytzcuintongo); f) (... aquizcotogo) (debajo de un lugar en la esquina inferior izquierda).

Es interesante observar que los primeros cinco de estos lugares están unidos por una línea rojo en el Lienzo de Otla. Es probable que se añadieron las glosas y la línea en el transcurso de algún conflicto.

\section{LOS PALACIOS DE OTLA}

En varios puntos en el espacio entre las dos barrancas aparecen parejas humanas sentadas frente a sus casas. Estas parejas representan matrimonios de nobles que tenían sus casas separadas de la gente común y regían y administraban a los campesinos de la población. Estos nobles ocupaban esta posición privilegiada por su nacimiento: se pasaban los derechos de administración sobre ciertas tierras y campesinos de gene-

\footnotetext{
${ }^{27}$ Van Doesburg 2001, 67, 68.

${ }^{28}$ El problema en el Lienzo de Nativitas es la representación de tres linderos entre este lugar y el Cerro Verde. Por lo tanto, y por los lugares que anteceden inmediatamente al "cerro de espinas", creí que esta serie representaba un área mayor.
} 

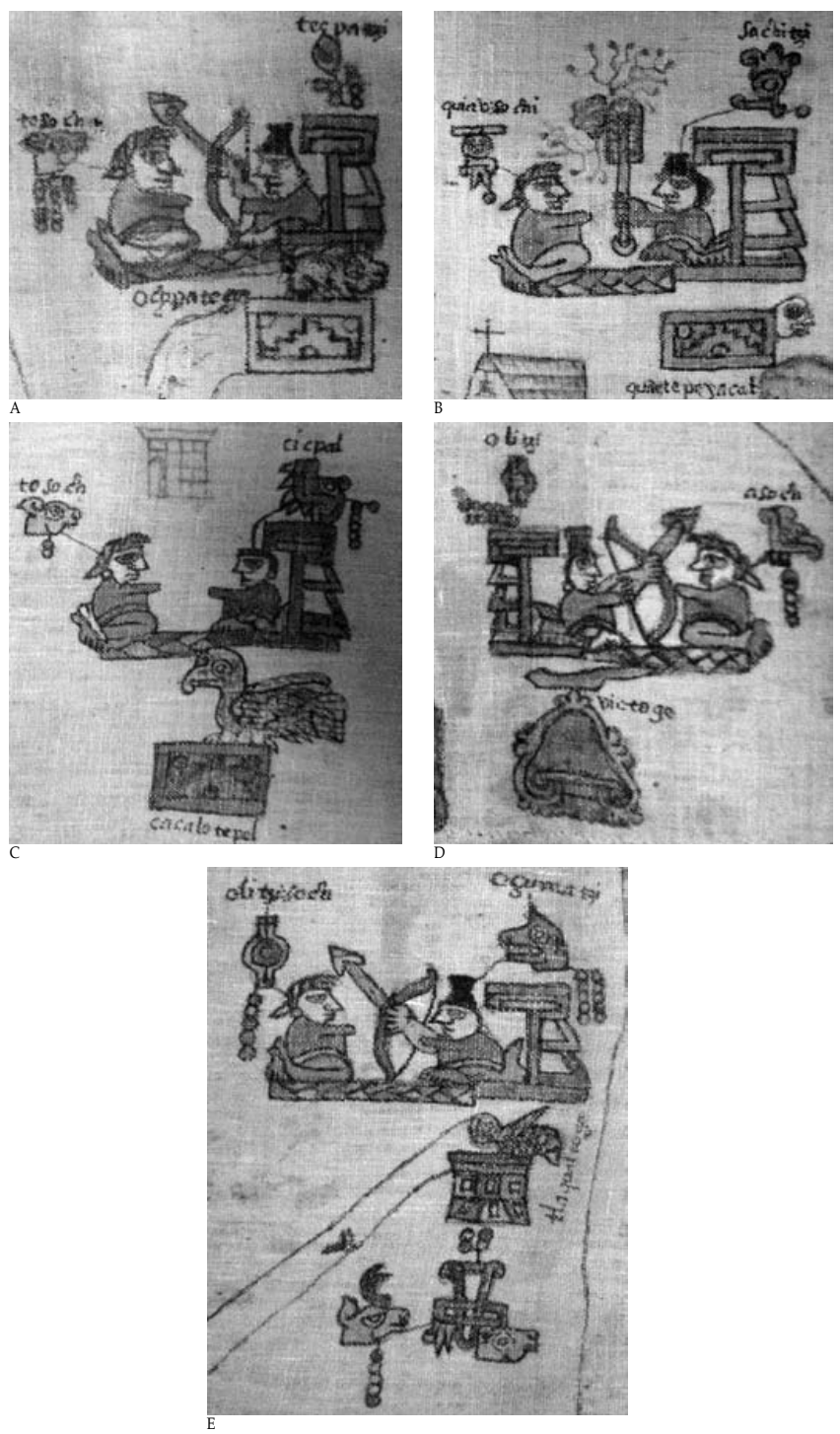

Figura 8. Las casas en el Lienzo de Otla. 
ración en generación. El lienzo sólo indica dónde estaban las casas de esta elite, pero -como es el caso en todos los lienzos del valle- no dice nada acerca de la población campesina. Esto es de alguna forma lógico, ya que los lienzos fueron pintados por encargo de los nobles o gobernantes y representan en primer lugar sus intereses. Los palacios estaban en los siguientes lugares (figura 8):

A) ochpatogo (ochpantongo), "en el pequeño lugar del camino real" (ochpantli - "camino real").29

GLIFO: un animal (no identificado) encima de un friso, de donde sale lo que podría ser un camino.

PAREJA DE NOBLES: señor 7-Pedernal (glosa: tecpatzi - "el venerable Pedernal") y señora 13-Conejo (glosa: tosoch [forma abreviada de tochsoch] "la flor Conejo").

B) qu(av)tepeyacal (qu(auh)tepeyacatl), "la nariz del cerro de águilas / árboles".

GLIFO: un friso con la cabeza de un espíritu de la tierra.

PAREJA DE NOBLES: señor 1-Flor (glosa: sochitzi - "el venerable Flor") y señora 1-Lluvia (glosa: quiavsochi - "la flor Lluvia").

C) cacalotepel (cacalotepetl), "cerro del cuervo".

GLIFO: un friso con un cacalote.

PAREJA DE NOBLEs: señor 7-Lagarto (glosa: cicpal - "Lagarto") y señora 2Conejo (glosa: tosoch - "la flor Conejo").

D) victogo (uictongo), "en el pequeño lugar de la pala" (uictli - "pala de madera").

GLIFO: una pala de madera sobre un cerro.

PAREJA DE NOBLES: señor (10)-Movimiento (glosa: olintzi - "el venerable Movimiento") y señora 5-Agua (glosa: asoch - "la flor Agua").

E) tlaqualtogo (tlaqualtongo), "en el pequeño lugar de comida" (tlaqualli - "comida").

GLIFO: un altar con lo que parece ser un pájaro (avispa, según Rincón, 2007).

PAREJA DE NOBLES: señor 10-Mono (glosa: oçumatzi - "el venerable Mono) y la señora 5-Movimiento (glosa: olitzisoch - "la flor la venerable Movimiento").

${ }^{29}$ Otra lectura posible es ochpate $[n] g o$, "en la orilla del camino real". 
Llama la atención la discrepancia entre los topogramas y las glosas en los casos A, B y E.

Estas casas nobles dispersas en el lienzo pueden ser el reflejo del tipo de organización sociopolítica de los yuhuitayu posclásicos en que las casas de los nobles tenían un patrón disperso, distribuidas por los siqui. Lo que no está representado en el lienzo son las relaciones que seguramente existieron entre las parejas representadas. ¿Todas estos matrimonios eran contemporáneos o representan generaciones dentro de un linaje que se fue cambiando de sede? Un ejemplo de este último escenario está en el Lienzo de Tulancingo, donde se muestran nueve parejas -cinco de ellas frente a sus palacios-distribuidas por el territorio de Ihuitlán. Sólo mediante la comparación con otros documentos es posible saber que éstas representan las generaciones 3,4 , 6y 14, 15, 16, 17 y quizás 19 de un solo linaje que se mudó de sede en varias ocasiones. ${ }^{30}$ Tampoco se indica la temporalidad: ¿Estas parejas eran los fundadores de sus casas o eran los que vivieron en la época de la conquista? Los tres personajes que apuntan con sus flechas (A, D y E) parecen ser los fundadores, tomando posesión mediante la guerra. ${ }^{31}$ Para las personas del siglo XVI, estas preguntas no eran relevantes, ya que la tradición oral que acompañaba estos documentos aclaraba sin duda estos detalles. Regresamos a esta discusión después de repasar la documentación sobre Otla del siglo XVI.

\section{LA CONGREGACIÓN DE OTLA}

A mediados del siglo XVI, al formarse la sociedad colonial en la Nueva España, la población campesina y los nobles fueron convencidos para reunirse alrededor de las nuevas iglesias fundadas por los frailes de Coixtlahuaca. Los frailes ya no aprobaron el patrón de asentamiento disperso y quisieron a la gente en un solo lugar para poder mejor evangelizarla y administrarla. El cambio fue muchas veces acordado con los gobernantes

\footnotetext{
${ }^{30}$ Doesburg 2000. En este caso, el linaje se dividió con el tiempo en cuatro "ramas", cada una con su palacio. Sin embargo, se trata aquí de un centro de tamaño e importancia mayor.

${ }^{31}$ Véase Oudijk 2002, para una amplia discusión de la simbología de la toma de posesión.
} 
y nobles locales, aunque hubo también casos de resistencia. Este proceso de concentración ocurrió en toda la Nueva España con resultados muy diversos. ${ }^{32}$ Algunas congregaciones resultaron exitosas, otras se desintegraron pronto. ${ }^{33}$ Las epidemias terribles que azotaron a la población a lo largo del siglo XVI hicieron necesario proponer nuevas congregaciones todo el tiempo, así que aun a finales del siglo XVI se estaba reorganizando a la población indígena. Esta reorganización de los asentamientos, que a la sazón se llamaba "congregación", transformaba la manera en que estos asentamientos humanos estaban espacialmente organizados. El resultado fue el cambio del patrón de asentamiento de uno con características dispersas, a uno con un carácter nuclear: el origen de los actuales pueblos.

Ahora, volviendo nuestra atención hacia el Lienzo de Otla, sobre la loma entre las dos cañadas - precisamente en el lugar donde hoy está asentado Otla-aparece un asentamiento representado por una iglesia y varias casas. Por el estilo del dibujo, se nota que éste no era parte del diseño original, sino que fue añadido posteriormente. Al lado tiene una glosa-diferente y muy posterior a las demás- que dice san geronimo nuebo, o sea éste lugar representa el actual pueblo de San Jerónimo Otla, donde se congregaron los nobles y campesinos durante el siglo XVI. Cerca de la iglesia se marca un manantial y un arroyo que baja al río Piaña, elementos indispensables en la nueva fundación. ${ }^{34}$ Contrastando el pa-

${ }^{32}$ La bibliografía acerca de las congregaciones civiles en la Nueva España es amplísima. Véase, por ejemplo, el listado en Jarquín Ortega 1994, 9, nota 1 y también Quezada 1995. Sin embargo, la gran mayoría de estos estudios enfocan el segundo periodo de congregaciones, ocurrido entre 1598 y 1606. Sobre las congregaciones tempranas, implementadas entre 1551 y 1564, existe poco material. Véase Gerhard 1977 para un importante resumen de casos tempranos, p.e. Teposcolula y Tlaxiaco de 1552 y 1553 . Véase también Chance 1986, 175 para otro resumen de casos en Oaxaca. En el valle de Coixtlahuaca, se hicieron congregaciones en Tequixtepec y Ihuitlán en 1563 por orden de García de Salamanca. Después de la salida del juez, algunos principales locales se encargaron de seguir la distribución de solares siguiendo la traza diseñada por el juez (Doesburg 2002, 23).

${ }^{33}$ San Mateo Tlapiltepec (separada de su congregación en Ihuitlán en 1583), San Antonio Acutla (rehusó a congregarse en San Miguel Tulancingo) y Tepetlapa (rehusó a congregarse en San Miguel Tequixtepec en 1563), para mencionar algunos ejemplos del valle de Coixtlahuaca (Doesburg 2001, 221-226 y 312 para Tepetlapa. Doesburg, en preparación para Tlapiltepec).

${ }^{34}$ Es de notar que arriba de Ochpantongo hay una segunda iglesia pintada con una casa (quizás inacabada) en frente. Viendo el estilo de dibujo de las dos iglesias y de las 
trón de palacios de nobles dispersos con la posterior representación de una comunidad nuclear, el lienzo sugiere que hubo una congregación de las casas nobles en la comunidad de San Jerónimo Otla. De hecho, los documentos indican un proceso complejo de congregaciones y separaciones en esta área.

Como indica Rincón $(2007,80)$, se realizó una congregación temprana en 1556. En un documento de 1591 se dice:

abra treinta y çinco años poco mas o menos [1556] que Luis Deza [sic], jues de comiçion nombrado por el virrei don Luis de Velasco, mi padre y entesessor [sic] en el govierno desta tierra, fue a esa provincia e iso junta de çiertos barios que estavan ypartados [sic] y devididos del dicho pueblo de San Xpoval [Suchixtlahuaca] e iso y formo con ellos un bario que llaman Pocotla, parte mui comoda, donde dio y rrepartio a los naturales que alli poblaron tierras y solares; $y$ mediante esto an bibido en buena trasa y pulisia acudiendo a su cabesera a misa y dotrina y a los demas [que] son obligados como todo consta del testimonio y autos que sobre ello pasaron de que hazian demostraçion. ${ }^{35}$

Según otro documento, esta congregación afectó varias comunidades en la región de Coixtlahuaca; en un texto de 1571, las autoridades de Coixtlahuaca señalan que: "habrá tiempo de catorce años poco más o menos [1557] [...] Luis Daza, juez de comisión que vino por mandado del ilustrísimo señor visorrey don Luis de Velasco a nos congregar y juntar, como lo hizo en toda nuestra provincia". ${ }^{36}$

Sin embargo, en 1591, un grupo de nobles se estaba separando de esta primera congregación. En el primer documento citado arriba, se le acusa a Diego Ortiz y a Domingo de la Serna de instigar a (parte de) la población para que la regresara a su lugar de origen:

casas, parece que esta segunda iglesia es de la misma mano que dos de las casas en San Jerónimo Nuevo. Esto se nota por la similitud en la base escalonada y en las tres almenas en el techo. Otras casas en San Jerónimo Nuevo parecen ser de otra mano menos diestra: por ejemplo, las hiladas de piedras no son horizontales, sino verticales.

${ }^{35}$ Archivo General de la Nación, Indios, vol. 5, exp. 279 (1591). Desafortunadamente, no he podido localizar el testimonio y los autos mencionados.

${ }^{36}$ Archivo General de Indias, Escribanía 160B, f. 843 (1571). 
an procurado desb(ar)atar y despoblar la dicha poblaçion y llevar a los naturales del a(l) çi(tio) antiguo donde antes estavan, questa a la falda de un monte parte mui lexos y desacomodada de la cabesera, queriendo hazer ygleçia y pueblo por si y sustraidos de la obedençia que deven a la parte donde estan sujectos, y que pues por sedula de su Magestad esta mandado se rredusgan y congreguen semexantes poblesuelos quando son pocos de su prençipio a las cabeseras y partes mas comodas.

Otros documentos confirman que el separatista Diego Ortiz era un personaje prominente de San Cristóbal y no solamente un "indio revoltoso" como le acusaron. Por ejemplo, en 1576, Diego Ortiz es mencionado como un natural de Ocotlan - quizás el mismo Pocotla-, sujeto de San Cristóbal Coixtlahuaca, que recibe ciertos privilegios. ${ }^{37}$ Como sugiere Rincón, Pocotla y Ocotlan pueden ser variantes del nombre de Octla, sugeriendo que Octla fue una congregación temprana cerca de San Cristóbal. ${ }^{38}$ Otros documentos aseguran -quizás idealizando el éxito de las congregaciones- que toda la población, incluyendo Octla, estaba congregada en San Cristóbal por estos años. Como sugiere el mismo texto citado arriba, la congregación de San Cristóbal debió realizarse antes de 1556 y de hecho su iglesia está representada en el Lienzo de Tlapiltepec. ${ }^{39}$ Según algunos documentos, en ella se congregaron cinco siqui: Oscuautla, Chila, Sosolatongo, Poscuautla o Octla, y Xuxuytongo. ${ }^{40}$ De los prin-

${ }^{37}$ Archivo General de la Nación, General de Parte, vol. 1, exp. 774, f. 151 (1576) y exp. 833 (794), f. 154 (1576). Licencias para un telar de jerga y para 200 ovejas. Ocotlán es mencionado también en Archivo General de la Nación, General de Parte, vol. 1, exp. 749, f. $147-147 \mathrm{v}, 1576$.

${ }^{38}$ Rincón $(2007,80)$, aunque él lee Xocotla. Aquí es interesante la representación del topograma para Octla (una jícara con pulque, octli, y dientes para representar el sufijo tlan) en el Códice Mendoza, f. 44, donde se quiere representar probablemente a Ocotlan (hoy Ocotlán de Morelos). Sin embargo, las dos variantes tienen un significado muy distinto: Ocotlan, "lugar de ocote" y Octla, "lugar de pulque".

${ }^{39} \mathrm{El}$ Lienzo de Tlapiltepec representa una iglesia con capilla abierta en San Juan Bautista Coixtlahuaca e iglesias sencillas en San Cristóbal e Ihuitlán. Ubica capillas en Aztatla, Texcalhueyac y lo que podrían ser Jicotlán y Teotongo. Curiosamente, también representa templos de tipo prehispánico en Jicotlán, Ihuitlán, Tequixtepec, Tlapiltepec y Otla (representado como "cerro de nopal").

${ }^{40}$ En la petición para la composición de 1582 (véase la nota 45), los nobles de San Cristóbal, "a vuestra merced pedimos y suplicamos las veces que podemos y de derecho 
cipales de estos barrios, sólo los dos nobles de Chila llevan el título "don", indicando una posición especial para este siqui dentro de la congregación. ${ }^{41}$ Ahora, en la composición territorial de San Cristóbal de 1582, Diego Ortiz y Francisco Jiménez aparecen como principales del siqui llamado Poscuautla o Octla ${ }^{42}$, aún congregado en San Cristóbal. De este barrio se dice que originalmente, antes de la congregación, estaba en la cercanía del actual Otla. La parte relevante del título reza:

[el alcalde mayor] salió de la dicha estancia [de San Cristóbal] por un camino que va hacia la estancia de Santa Maria y llegados encima de un cerro como un cuarto de legua de el dicho pueblo de San Xptobal en un sitio donde había muchas casas caídas y árboles de morales y zapotes y magueyales $\mathrm{y}$ corrales de ganado menor que el dicho gobernador, alcalde[s] y regidores y demás indios que allí iban por lengua de los dichos intérpretes dijeron ser allí el sitio antiguo de el barrio de Sosotlantongo que [ahora] estan poblados [en] la dicha estancia [y] pueblo de San Xptobal. [...] Saliendo de el dicho sitio arriba nombrado [yendo por la dicha loma arriba nombrada] por un camino que va hacia el monte, llegados [del] dicho sitio a una loma en la [mesma derechura/manderecha] del sitio arriba nombrado como media legua pequeña, donde había muchas [casillas/ casas] caídas y árboles de morales y sapotes y de la parte de la dicha quebrada había [por toda/encima de] una loma muchas [casillas/casas] caídas y árboles [de morales] [y se

[haya] lugar vuestra merced vaya al dicho pueblo de San Xptobal y vea por vista de ojos todos los sitios antiguos donde estábamos poblados, cinco barrios, que a la presente estamos y vivimos en el dicho pueblo de San Xptobal, donde tenemos nuestras tierras y árboles y dello nos sustentamos". En este mismo texto se describe la ubicación original de estos cinco barrios, por lo que se entiende que Chila estaba hacia el poniente de Otla, colindando con Tejupan, o sea, precisamente donde la glosa en el Lienzo de Otla ubica la división con las milpas de Chila.

${ }^{41}$ Según el documento de la composición de 1582 (véase la nota 45), ellos fueron don Andrés de Castilla y don Juan Bautista. Quizás Chila corresponde al lugar "altar de la joya" que está representado en la ubicación de Chila en el Lienzo de Tlapiltepec y el Lienzo A. Esta información documental encuentra una confirmación interesante en la zona arqueológica grande que se encuentra en las lomas al poniente de Suchixtlahuaca, justo donde la composición de 1582 ubica a las ruinas de Chila (véase la nota anterior).

${ }^{42}$ La etimología de este topónimo no está claro. Quizás es Poxcauhtlan, "lugar de moho". Un lugar con este nombre existe en la Sierra de Zongolica (véase Códice Mendoza f. 10v). Además parece ser la forma subyacente del nombre del río Puscatán en Tabasco. 
reconoció/ que parecía] haber sido poblado, que los dichos gobernador, alcaldes y demás indios que allí estaban [por] las dichas lenguas dijeron ser el sitio antiguo de el barrio [nombrado] [Poscuautla/ Puesquautla] que ahora están poblados en el dicho pueblo de San Xptobal y ser los principales del dicho barrio Diego Ortiz, Fransisco Ximenes y Xptobal Lopes; y más arriba por el dicho camino que iba hacia el monte arriba como tres cuartos de legua de las dichas casillas, [y] llegados a un sitio que se nombra [Yacuqu(..)/ Yazuquin] estaban unos corrales de ganado menor que dijeron tener allí los ganados [del dicho barrio/de dichos barrios] de la comunidad y de los [dichos] barrios de Chila y Sosotlatongo y ser de el dicho barrio los dichos corrales y [partir] términos con el pueblo de Santa Maria [en un cerro] que se llama Yucutiyagua y con el pueblo de Texupa [*en] otros dos cerros nombrados Tuuyna [sic pro: Ytnuyna] y Tutuyeque; y por aquellas quebradas había muchas sementeras de maizales y en una quebrada antes de llegar al dicho corral había muchos [árboles de] manzanas y árboles de membrillos que todas aquellas quebradas y montes y tierras que el dicho señor alcalde mayor anduvo [*declararon] ser tierras de el dicho barrio [de] [Ustla/O(s)tla] que ahora esta poblado en el dicho pueblo de San Xptobal (cursivas mías). ${ }^{43}$

De este texto se entiende -aunque de una manera poco clara-que Poscuautla y Octla son de alguna manera nombres distintos para un mismo lugar que originalmente estaba en la cañada del río Piaña, a la altura del actual Otla (a $3 / 4$ legua, o sea de 3 a 4 km de Suchixtlahuaca ${ }^{44}$ ) y colindaba con Santa María Nativitas y Tejupan en tres de los linderos representados en el Lienzo de Otla.

En 1586, Diego Ortiz y su colega Francisco Jiménez aparecen -junto con otros nobles de San Cristóbal- entre los principales acusadores con-

${ }^{43}$ Archivo de Bienes Comunales de San Cristóbal Suchixtlahuaca. Copia del año de 1683 de los titulos de San Cristobal (1582). El documento original de 1683 se conserva en el Archivo General Agrario, México, clasificación 276.1 / 685. Existe una segunda copia en el Archivo de Bienes Comunales que tiene algunas variantes en el texto. Estas aparecen marcadas por corchetes. Ostla parece ser un error del copista por Octla.

${ }^{44} \mathrm{La}$ legua es la distancia que se puede andar en una hora. Es una medida itineraria que varía según el camino. Normalmente, oscila entre 4 y $5.5 \mathrm{~km}$. Sosolatongo se conoce hoy como Sosola y está donde este documento lo describe (un kilómetro en la dirección de Santa María), sobre un sitio posclásico (véase el mapa en el sitio de internet de Kowalewski). 
tra el cacique de Tequixtepec en un juicio por "idolatría" y malos tratos, pero probablemente con un trasfondo político sobre el control de algunas tierras en los límites de los dos pueblos. ${ }^{45}$ En 1588, los mismos Diego Ortiz y Francisco Jiménez fueron parte de una comitiva de nobles y principales de San Cristóbal y de Santa María que intentó parar la introducción de ganado en la región por parte del español Francisco Guerrero. ${ }^{46}$ Sin embargo, tres años más tarde Diego Ortiz estaba gestionando la refundación de Poscuautla-Otla. También de 1591 es el siguiente texto que indica claramente la rivalidad entre San Cristóbal y Otla y que probablemente se relaciona directamente con el intento de separación:

Don Luis de Velasco etc. hago saver a vos, el corregidor del pueblo de Cuestlauaca, que por los naturales de la estançia deSan Xpoval, sujeto que dizen ser del dicho pueblo, se me a ffecho rrelacion que governando el arçobispo de Mexico ${ }^{47}$ hizo merçed a su comunidad de un sitio destancia para ganado menor en que al pressente ay quatroçientas y sesenta cabeças de obejas, de las quales se pagan cosas forçosas del comun y de la rrepublica y se acude a substento de yndios pobres y de los rreligiosos que les administran la doctrina y sacramentos; y que los yndios del barrio de Octla pretenden tener parte en el dicho sitio y ganado y benderlo para seguir pleytos y ynquietarlos como lo an yntentado causando rrebue[1]tas. ${ }^{48}$

Quizás, al congregarse Otla en San Cristóbal, fueron otorgadas las tierras que dejaba como estancia de ganado al pueblo de San Cristóbal, por lo que el regreso de la gente de Otla a estas tierras resultó en un conflicto.

\footnotetext{
${ }^{45}$ AAT-23, publicado en Doesburg 2002.

${ }^{46}$ Archivo de Bienes Comunales de San Cristóbal Suchixtlahuaca. Copia (siglo XVII) de un documento de 1588. En el archivo municipal de Nativitas existe un documento muy similar.

${ }^{47}$ Pedro Mayo de Contreras, arzobispo de México, era virrey de 1584 a 1585. Desafortunadamente, no he podido localizar los documentos relativos a esta merced, ya que los registros de estos años faltan en el Archivo General de la Nación.

${ }^{48}$ Archivo General de la Nación, Indios, vol. 5, exp. 1030 (1591). Es interesante ver que Francisco Jiménez pide una estancia de ganado precisamente en este año (Archivo General de la Nación, Indios, vol. 5, exp. 1115 (1591). Otla no era la única comunidad tratando de establecerse en este tiempo. También Tepetlapa estaba separándose de Tequixtepec.
} 
De hecho, la composición de 1582 menciona los corrales de ganado en este lugar.

No obstante, poco después, en 1593, se reconoció la existencia del barrio separado:

Don Luis etca. [...] el licenciado Geruer de el Corral, fiscal de su Magestad en esta rreal audiencia, me hizo rrelaçion que [...] se hauia hecho ynstançia por don Joan, gouernador de el dicho pueblo de Cuestlauaca, para que los naturales de el dicho barrio de Octla su su [sic] subjecto se congregasen a su caueçera, haziendoles derriuar, como se le ayan derriuado, sus cazas e yglesia, por gozar el dicho gouernador de las tierras que dexauan en el dicho barrio, rrespecto de ser [estas tierras] acomodadas para sus granjerias donde thenia ya hechos corrales para sus ganados, en que [los de Octla] auian rresçeuido y rresçiuian notorio agrauio y perjuiçio, pidiendome mandase rremediarlo de manera que los dichos naturales pudiesen libremente rresidir en el dicho barrio y rreedificar sus cazas e yglesia. ${ }^{49}$

El virrey ordenó "que a los yndios de el barrio de Octla no los compelan mudar a su cabeçera". ${ }^{50}$ Se trata aparentemente de un conflicto entre don Juan Bautista, gobernador de Coixtlahuaca ${ }^{51}$, y los nobles de Otla. Quiero señalar que a don Juan Bautista ya lo conocimos arriba como uno de los dos nobles gobernantes de San Cristóbal, del siqui de Chila, que llevaban el título "don" en su nombre. Por lo tanto, podría interpretarse este conflicto como un intento del gobernante de Chila de evitar la separación del siqui de Octla.

De paso noto que el gobernante de San Cristóbal logró ocupar la posición de gobernador en la cabecera debido a cambios en la organización política local: como noté en la primera parte de este texto, a partir de 1574 la posición de gobernador ya no estaba en manos exclusivas de los descendientes del principal linaje de Coixtlahuaca, sino alternaba entre los nobles mayores de San Cristóbal y Coixtlahuaca.

\footnotetext{
${ }^{49}$ Archivo General de la Nación, Indios, vol. 6 (2), exp. 811 (1593).

${ }^{50}$ Relacionado con este asunto: Archivo General de la Nación, Indios, vol. 6, exp. 797, 1593: para que las autoridades encargadas de la congregación de Otla, por el tiempo de agua y hasta su señoría mande otra cosa, congregue los naturales en San Cristóbal.

${ }^{51}$ Archivo General de la Nación, Indios, vol. 6 (2), exp. 845 e Indios, vol. 3, exp. 233.
} 
El intento de evitar la separación era inútil y Octla se refundó. De hecho, de los cinco siqui congregados en San Cristóbal en 1556, cuatro quedan congregados en San Cristóbal hasta hoy, pero Otla está separado. ${ }^{52}$ Con la construcción de su iglesia debe haberse establecido el altar del Santo Patrón San Jerónimo y a partir de esta fecha se conoció el pueblo como San Jerónimo. Aparte de su santo, el pueblo obtuvo una regiduría en el cabildo de Coixtlahuaca. Es probablemente en este momento que se añadió el dibujo de la iglesia y de las casas del nuevo asentamiento.

Por último, en 1596, ya bien establecida la comunidad de San Jerónimo, se acusó a Francisco Jiménez, regidor de esta comunidad, de haber cobrado tributos indebidos. ${ }^{53} \mathrm{El}$ texto revela un conflicto entre este noble, regidor de San Jerónimo en el cabildo de Coixtlahuaca, y el tequitlato del siqui. En el documento relacionado con este caso se confirma además con claridad que Posquautla y Otla son una cosa: el principal acusador-testigo del caso

dixo llamarse Juan Garcia y ser natural de estançia de San Geronimo del barrio de Puxquatla [y] dixo que conose al dicho Francisco Ximenez en ella contenido desde que a que se sabe acordar el qual sabe este testigo que sin tener derecho ninguno se a hecho mandon de la estancia y barrio de San Geronimo del qual este testigo a un año que es tlequitato y por mandado del dicho Francisco Ximenez a cobrado de muchos yndios del dicho barrio cantidad de pesos de oro, mantas y gallinas.

Además,

como es publico e notorio ellos tienen ya en punto de acabar la yglesia del conuento de este pueblo, a donde acuden a trabaxar quando les uiene su tanda; y quel dicho Francisco Ximenez les dise que le den quatro rreales

\footnotetext{
${ }^{52}$ Doesburg y Swanton, en preparación. Hasta finales del siglo XX, Suchixtlahuaca conservaba cuatro "Sociedades Agrícolas" llamadas Escotla, Chila, Sosola y Sosoitongo o Siositongo, las cuales son las obvias equivalentes de cuatro de los siqui mencionados en el siglo XVI. La ausencia de Poscuautla de esta lista se explica por la separación de Octla

${ }^{53}$ Archivo Histórico Judicial de Oaxaca, Tepozcolula, Criminal, Caja 1, doc. 52, 1596.
} 


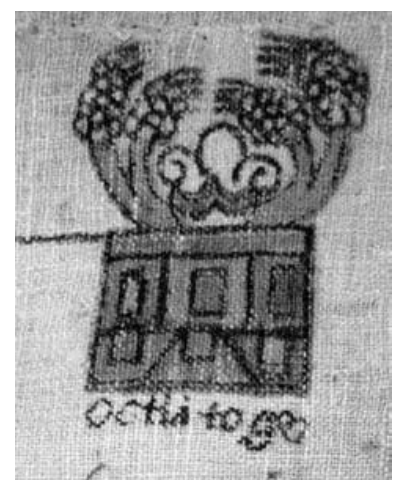

FIGURA 9: Octlato[n]go, San Jerónimo el viejo.

cada yndio quando le cayere su suerte, y que el los librara y assi lo a hecho y tenido por uso y costumbre. ${ }^{54}$

De regreso al lienzo, llama la atención la ausencia de un glifo para Poscuautla. Por otro lado, el documento indica dónde estaba el primer asentamiento de Otla: hacia el norte, sobre la loma y cerca de los límites con Suchixtlahuaca, está un lugar sin nobles y sin población, que se llama octlatogo (octlatongo - "en el pequeño lugar de Octla (lugar del pulque"). Su glifo consiste en un corazón o camote (se dibujaba de la misma manera) con unos tallos de una planta floreada o con frutos sobre un altar (figura 9). Un glosa, de la misma mano tardía que la de "San Jerónimo Nuevo", indica San geronimo el biejo.

\section{Relaciones CON COIXTLAHUACA}

La casa de la pareja de nobles llamados el señor 10 Mono y la señora 5 Movimiento tiene algunos detalles que sugieren que se trataba de una pareja de nobles de importancia: un camino que llega a Tlaqualtongo

\footnotetext{
${ }^{54}$ Los de San Cristóbal ya habían insistido antes, en 1591, en el término del servicio en la iglesia y el convento de Coixtlahuaca. Archivo General de la Nación, Indios, vol. 3, exp. 788.
} 


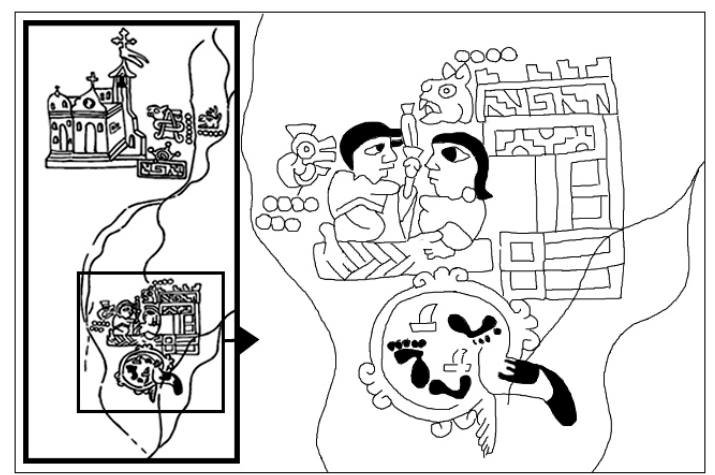

FiGURA 10: Los gobernantes señor 4 Ocelote y señora 7 Viento en "Piedra, huellas y cola" (Lienzo de Tlapiltepec). Dibujo adaptado de Nick Johnson.

indica que esta pareja venía de afuera, de fuera de Otla, de un lugar llamado tiçaltogo (tiçatongo), "en el pequeño lugar de tiza" (tiçatl - "barniz o tierra blanca"). El glifo de este lugar parece representar una piedra blanca colocada en llamas sobre un cerro. No sabemos dónde existió este lugar Tizaltongo, pero su ubicación en el lienzo sugiere que su ubicación era quizás hacia el norte de Otla y fuera de sus límites. Tizaltongo tiene una fecha: año 1 Casa, día 8 Perro. ${ }^{55}$ La fecha de Tlaqualtongo es año 4 Conejo, día 5 Venado. Estas fechas asociados a los lugares funcionan como fechas sagradas que simbolizan la fundación de estos lugares. Sobre todo la segunda fecha fue de gran importancia en Coixtlahuaca y -como veremos más adelante- aparece en varios documentos de la región. El lienzo también indica que Tizatongo era el lugar de origen de otra pareja: un segundo camino sale de Tizatongo y llega a un lugar cuyo glifo y glosa (quizás [...]qui [x/z]p[...]) presentan problemas de interpretación. Allí están sentados el señor 4 Ocelote (su glosa está muy borrada, quizás intencionalmente) y la señora 7 Viento (yeecasoch, "la flor Viento"). Por la información proporcionada en los lienzos de Coixtl-

${ }^{55}$ Parece que esta fecha no aparece en ningún otro documento del grupo. Hay que tomar en cuenta que los numerales 1 y 8 son intercambiados en algunos documentos, así que los coeficientes del año y del día pueden cambiar de documento en documento. 
ahuaca sabemos que ellos eran gobernantes de Coixtlahuaca. Sobre todo el Lienzo de Tlapiltepec ofrece una escena muy similar (figura 10). ${ }^{56}$ El lugar está representado cerca de la junta de los ríos Piaña y Culebra (las líneas onduladas alrededor de la pareja), quizás el sitio del mercado prehispánico. El señor 4 Ocelote era descendiente -en décima generación- del fundador de uno de los principales linajes gobernantes de la región (figura 11). Él y su padre (11 Flor) vivían en un época importante, ya que en sus vidas ocurrió la fundación de la ciudad de Coixtlahuaca, a mediados del siglo XIII. Uno de los eventos cruciales durante el proceso de esta fundación fue la reunión con un grupo de señores, probablemente procedentes del norte, de lo que hoy es el estado de Puebla. La identidad y la razón para la participación de estos "poblanos" en la fundación de Coixtlahuaca no es conocida, pero el evento está representado en por lo menos cuatro documentos. ${ }^{57}$ En el Lienzo de Coixtlahuaca II vemos a los gobernantes 12

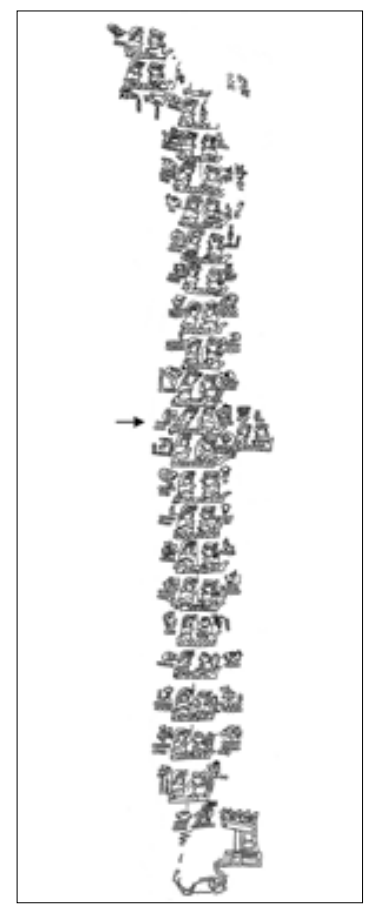

FIGURA 11: El linaje del señor 4 Ocelote (Lienzo de Tlapiltepec). Dibujo de Nick Johnson. Lagartija, 11 Flor y 12 Agua, los representantes de los tres linajes principales, reunidos. En el Lienzo de Tlapiltepec son 1 Viento (hijo de 12 Lagar-

${ }^{56}$ En un estudio anterior $(2001,76,77)$ sugerí que el topograma sobre el cual están sentados 4 Ocelote y su esposa podría ser igual a uno de los linderos en el Lienzo de Nativitas (caahiñaña, "cadera de felino"). Sin embargo, posteriormente, una foto de detalle del Lienzo de Tlapiltepec me hizo dudar sobre mi identificación del glifo como la cadera de un felino. El glifo consiste en una piedra con lo que parece ser una cola de felino. En su interior se aprecian unas huellas de pies humanos y unas uñas. El glifo en el Lienzo de Otla también contiene las huellas. Estas pisadas representan el concepto "tianguis", por lo que la primera parte de la glosa quizás podría reconstruirse como $\left({ }^{*}\right.$ tian $) q u i z p(. .$.

${ }^{57}$ Lienzo de Tlapiltepec, Lienzo de Coixtlahuaca II, Códice Baranda y Lienzo de Tulancingo. 


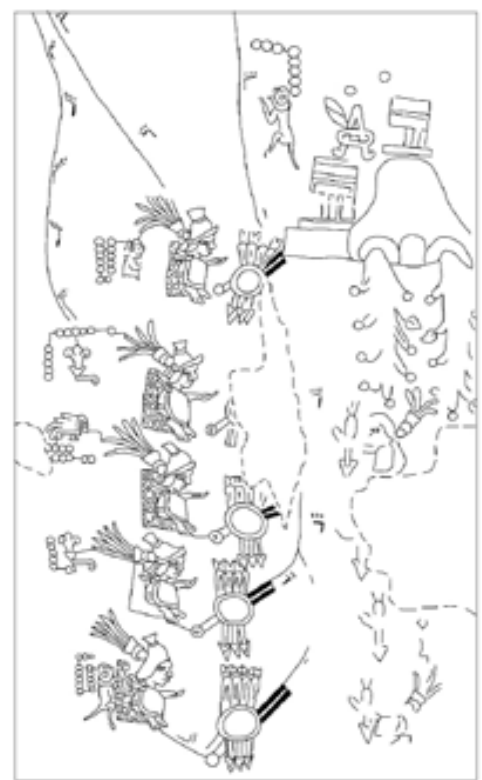

Figura 12a. La reunión de los fundadores de Coixtlahuaca (Lienzo de Coixtlahuaca II).

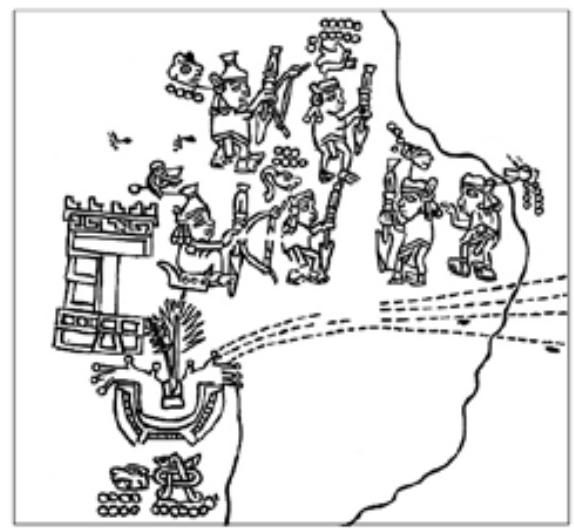

Figura 12b. La reunión de los fundadores de Coixtlahuaca (Lienzo de Tlapiltepec). Dibujo de Nick Johnson. 


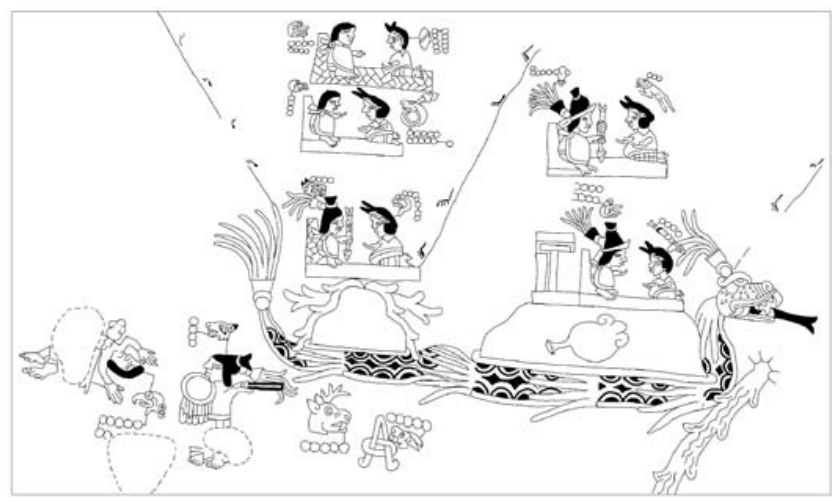

Figura 13. El señor 4 Ocelote y la señora 7 Viento sobre "Cerro de Sangre" de Coixtlahuaca (Lienzo de Coixtlahuaca II).

tija), 4 Ocelote (hijo de 11 Flor) y 12 Agua (figuras 12a y b). Otro de los rituales de fundación se desarrolló alrededor del altar tolteca de Tulancingo. De nuevo, en el Lienzo de Coixtlahuaca II, entre los participantes están los señores 12 Lagartija, 11 Flor y 12 Agua. En otras escenas se representa al señor 4 Ocelote con su esposa 7 Viento como fundadores de una parte de la ciudad de Coixtlahuaca (figura 13).

Del petate en que están sentados el señor 4 Ocelote y su esposa en el Lienzo de Otla sigue un camino que termina en un glifo que consiste en un remolino rojo, probablemente de sangre, encima de un cerro, ubicado frente al lindero Oceloticpac. La flecha apuntada hacia el interior del palacio del lugar indica que el señor 4 Ocelote -o un descendientetomó el lugar mediante una conquista o un ritual militar de toma de posesión. El lugar tiene una fecha asociada: año 4 Conejo, día 5 Venado, o sea es la misma fecha que la de Tlaqualtongo. Esto sugiere una relación estrecha entre los dos lugares. Este último glifo (o un variante: remolino de sangre ${ }^{58}$ sobre un friso, sangre sobre un cerro) y la misma fecha (o un variante: año 5 Conejo, día 5 Venado; año 6 Conejo, día 4

${ }^{58}$ En publicaciones anteriores sustuve que se trató de un remolino de agua (Doesburg y van Buren, 1997, 127).Sin embargo, la comparación entre documentos y el color rojo muy tenue en el Lienzo de Coixtlahuaca y en el Lienzo de Tlapiltepec me convencieron que se trata de sangre. 


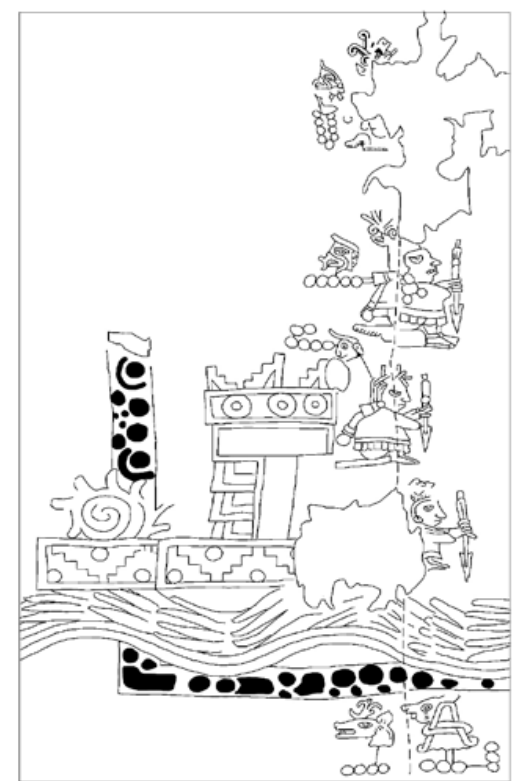

Figura 14a. "Friso de Remolino de Sangre" de Coixtlahuaca (Lienzo de Coixtlahuaca).

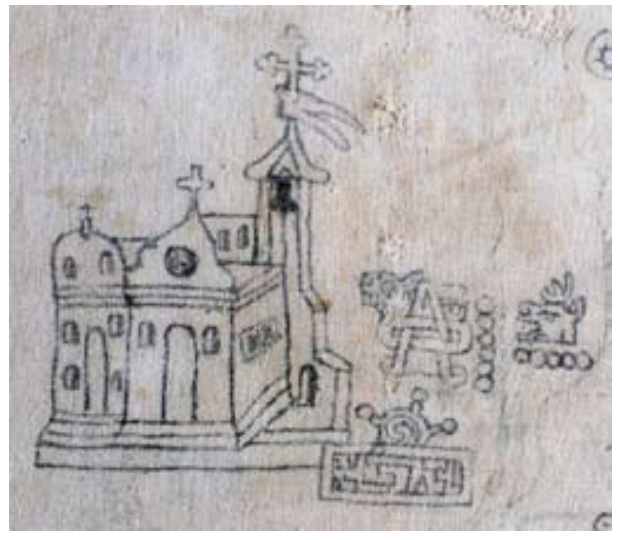

Figura 14b. "Friso de Remolino de Sangre" y el convento de Coixtlahuaca (Lienzo de Tlapiltepec). Cortesía del Museo Real de Ontario, Canadá (@ ROM). 
Venado; o año 6 Conejo, día 5 Venado $^{59}$ ) aparecen en los lienzos de Coixtlahuaca como indicativos del lugar donde los dominicos fundaron el complejo conventual (figuras 14a y b). El actual exconvento se ubica de hecho aproximadamente frente a Peña de León, mencionado arriba y tal como lo representa el Lienzo de Otla. El Lienzo de Coixtlahuaca y el Lienzo de Coixtlahuaca II confirman que allí reinaron los descendientes de 4 Ocelote. Como dijimos al inicio de este texto, después de la muerte de Atonaltzin, el linaje gobernante se asentó en "cerro de sangre". Es allí donde reinó el conocido Cozcacuauhtli, aliado de los mexica, en la primera década del siglo XVI.

Ahora, el camino bifurcado que lleva tanto a Coixtlahuaca como a Otla y sus fechas sagradas coincidentes sugieren que la conquista de Tlaqualtongo era parte de la fundación-conquista de Coixtlahuaca. En este escenario, los tres hombres que apuntan sus flechas serían "capitanes" de 4 Ocelote, fundando sus casas en la parte recién conquistada. Está relación entre 4 Ocelote y los nobles en la parte austral del valle está confirmada por información en otros documentos: los lienzos de Coixtlahuaca y el Lienzo de Nativitas indican que 4 Ocelote se unió al señor de 8 Zopilote de "arroyo de piedras" (hoy Santa Catarina Ocotlán) en la conquista de la parte sur del valle, en donde fundaron la casa noble de "cerro de pájaro" o "casa de peña" (hoy Santa María Nativitas). ${ }^{60}$ El señor 4 Ocelote también armó campañas contra Huautla y Zoyaltepec (figuras 15a y b). La estructura que se creó fue una de varias casas nobles dependientes de "cerro de sangre" en el sur del valle. A mediados del siglo XVI, esta estructura sufrió un proceso un tanto artificial de congregaciones, del cual surgieron Santa María Nativitas y San Jerónimo Otla como nuevos pueblos.

${ }^{59} \mathrm{El}$ Lienzo de Coixtlahuaca II tiene año 5 Conejo, día 5 Venado, el Lienzo de Coixtlahuaca tiene año 6 Conejo, día 4 Venado (aunque la conquista de 4 Ocelote hacia el sur, en límites de Zoyaltepec está fechada como año 6 Conejo, día 5 Venado) y el Lienzo de Tlapiltepec tiene año 6 Conejo, día 5 Venado. Esta variación es una curiosidad que no puedo explicar. 5 Venado y 6 Conejo son días consecutivos, una construcción común para fechas sagradas, por lo que prefiero pensar que esta fue la combinación intentada.

${ }^{60}$ Confirmación para la identificación de Río de la Piedra (lugar de origen de 8 Zopilote según el Lienzo de Nativitas) como Santa Catarina Ocotlán viene de varios planos del siglo XIX de los linderos de Coixtlahuaca, en que el lindero Yuchayu-ndaxu ("río de la piedra" en mixteco y chochona) coincide con la ubicación de Ocotlán. 


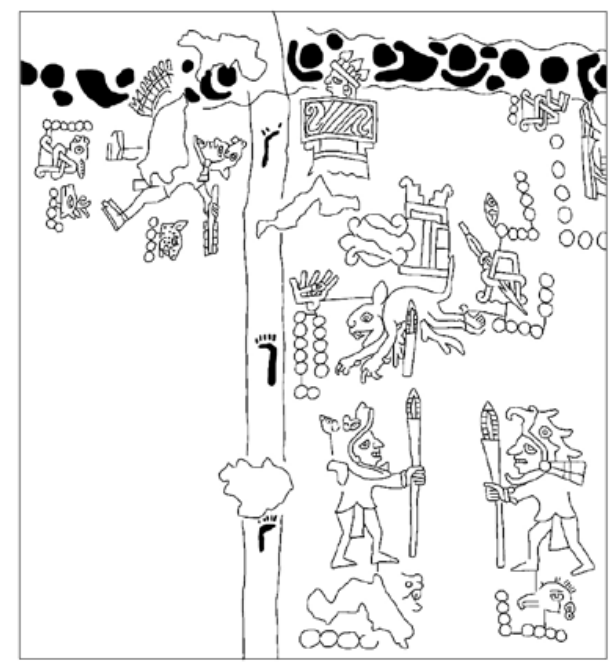

FigURA 15a. Los señores 4 Ocelote y 8 Zopilote conquistando al señor 12 Hierba cerca de Nativitas (Lienzo de Coixtlahuaca).

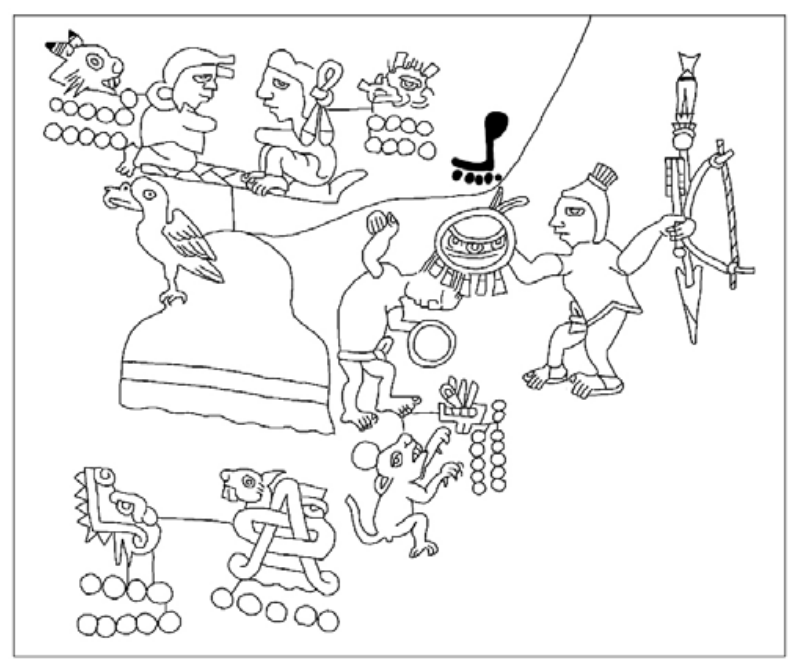

FigURA 15b. La captura del señor 12 Hierba y la entronización del señor 8 Zopilote cerca de Nativitas (Lienzo de Nativitas). 


\section{TRAZANDO LOS LINDEROS}

Uno de los pasos cruciales para lograr entender los documentos pictográficos es preguntarse porqué fueron elaborados. Pocos investigadores lo hacen. Sin embargo, esta pregunta nos ayuda a pasar del plano descriptivo al plano interpretativo. Es obvio que cada documento corresponde a una situación específica del momento de su creación y representa una aseveración o enunciación particular sobre algún tema de discusión o discordia. Cada documento quiere decir algo en el momento de su manufactura. En general, los documentos pueden ser vistos como instrumentos dentro de los procesos de negociación en el interior de los yuhuitayu o entre yuhuitayu y la administración española. Verlos como documentos estáticos y de contenido objetivo es malinterpretar su función dentro de la sociedad mesoamericana. Por otro lado, los documentos no revelan sus objetivos de manera aparente: es sólo a través de la reflexión sobre los temas incluidos (y excluidos) en el documento que podemos formar una conjetura circunstanciada.

Como hemos visto, en el Lienzo de Otla se incluyen tres temas: la serie de linderos, las parejas nobles y la relación genealógica de una de ellas con un linaje en Coixtlahuaca. Ahora debemos preguntarnos ¿A qué circunstancia puede corresponder esta selección de la información? En este caso, la lista de linderos es crucial para vislumbrar el objetivo del documento. Como es sabido, durante las primeras décadas del siglo XVI se incrementa la importancia de la definición de los territorios mediante la creación de una "raya" definida por linderos. Esto explica la gran cantidad de lienzos de la colonia temprana que se centran en el tema de los linderos. Este nuevo énfasis en la territorialidad de los yuhuitayu podría ser una influencia del concepto europeo del territorio y de su administración. Europa misma estaba pasando de una organización sociopolítica de tipo "feudal" (en que las relaciones personales de un grupo de personas con un señor eran el elemento vinculante del señorío) hacia una sociedad territorial. ${ }^{61}$ En el siglo XVI, los españoles, en su afán de impartir justicia en las numerosas escaramuzas y conflictos por tierras

${ }^{61}$ Sobre este cambio (usando los términos de los estudios de la época medieval europea Personenverband y Territorialverband), véase Ouweneel, 1990. 
entre los yuhuitayu, acudieron a la idea de unidades territoriales, estableciendo linderos precisos que marcaban los límites. En el caso del macroyuhuitayu de Coixtlahuaca, este proceso quedó registrado en el Lienzo de Coixtlahuaca, en el cual jueces españoles visitan el área en los años de $1527,1542,1544$ y 1552 para establecer los linderos. En otro lugar argumenté que la última visita la debió protagonizar el juez Gaspar de San Martín. ${ }^{2}$ Estas visitas, que ocurrieron anteriormente a las primeras congregaciones, deben haber tenido su impacto en la región. En 1559, Tequixtepec recordaba estas visitas -y la visita de Luis Daza-con detalle:

entre los de Cuestlavaca y nosotros tubimos pleito sobre los terminos de entre los dichos pueblos y por el Audiencia Rreal desta Nueba España fue declarado aver probado bien nuestra yntençion, dando por mal probada lo por el gobernador y prinçipales de Cuestlavaca [alegado], y sobrello se dio probision para que Gaspar de San Martin, corregidor que fue de Nochistlan, amoxonase los dichos terminos, el qual los amojono segun e por donde fue determinada por la dicha Rreal Audiencia, de la qual determinaçion ubimos [carta] executoria [...]. Y el pleito que entre nosotros y los del dicho pueblo dize ai, es que siniestramente los del dicho pueblo de Cuestlavaca hizieron çierta rrelaçion en la dicha Rreal Audiencia diziendo quel amoxonamiento fecho por el dicho Gaspar de San Martin era en su perjuiçio, sobre que se les dio una probision para que Luis Daça, correxidor que fue de Guaxuapa lo biese, despues de lo qual de nuestro pedimento se nos dio otra contraprobision para quel dicho Luis Daza hiciese guardar la dicha carta executoria [...]. ${ }^{63}$

Fue aparentemente en la visita de Luis Daza de 1556 que se aprovechó para comenzar el proceso de congregaciones.

La definición de los espacios de cada congregación mediante linderos iba a dar pie a la formación de la identidad de los pueblos actuales. El Lienzo de Tequixtepec I y el Lienzo de Nativitas ejemplifican la importancia de los nuevos linderos en los yuhuitayu menores. Desde este punto de vista, se vislumbra en el Lienzo de Otla una enunciación de sus parejas

${ }^{62}$ Doesburg 2003, 79. En Doesburg, en prensa, argumento que este proceso ya comenzó con la llegada de los mexica a la región.

${ }^{63}$ Doesburg 2002, 161-162. 
nobles en cuanto a un nuevo territorio: hemos visto que la congregación de la población de Otla-Posquautla en San Cristóbal, a partir de 1556, no caminó bien. Posiblemente ya en este momento ${ }^{64}$ los nobles hicieron un caso ante los gobernantes en Coixtlahuaca, argumentando la opción de constituir un yuhuitayu "colonial" definido por linderos. En este caso, los nobles mencionaron su lazo genealógico con uno de los linajes principales de Coixtlahuaca para demostrar su suficiente estatus social. Esta mención sirvió quizás también para enfatizar cierta afinidad étnica de este grupo de nobles, que posiblemente por órdenes de 4 Ocelotl habían colonizado o conquistado el área de Otla. Tal vez hubo cierta rivalidad entre el linaje gobernante de Coixtlahuaca y los gobernantes de San Cristóbal (Chila) que obstaculizó la integración de los nobles de Otla en la congregación de San Cristóbal. Es posible que la afiliación étnica de los dos principales linajes en Coixtlahuaca jugara un papel en esta estructuración política: mientras documentos de San Miguel Tequixtepec sugieren que el linaje de Atonaltzin se identificó como la parcialidad de pinocalco ("la casa de los ngiwa"), documentos coloniales de Coixtlahuaca identifican a "cerro de sangre" como un "barrio" de los mixtecos. ${ }^{65}$

Un hecho curioso es el parcial traslape de los linderos en el Lienzo de Otla y el Lienzo de Nativitas. Los dos lienzos incluyen en sus linderos la secuencia desde "cerro espinoso" hasta "peña del hueso". A parentemente, los nobles locales se disputaban esta zona desde la propuesta territorial de sus respectivos yahuitayu. Este mismo fenómeno, aunque en una extensión más reducida, ocurre más tarde en los títulos de San Cristóbal y Santa María Nativitas, ambos de 1582. En los títulos de Nativitas (del 30 de octubre) leemos:

subiendo por una loma arriba çerca de alli llegados a una loma nonbrada Ydt(nuñu) que junto a ella estaba una quebrada senbrada de maizales que

\footnotetext{
${ }^{64}$ El estilo del documento sugiere una fecha anterior a 1560. A partir de esta fecha, cuando mueren los últimos maestros formados en la época prehispánica, la pictografía va perdiendo terreno rápidamente.

${ }^{65}$ Van Doesburg 2001, 45-46. El barrio de Iztepec ("cerro de sangre") se menciona en Archivo General de la Nación, General de Parte, vol. 1, exp. 1182 de 1576. Documentos de Nativitas y San Jerónimo indican que por lo menos una parte de la población (y la elite) de estos lugares era de habla mixteco.
} 
yba açia la est[anci]a de San Xpoual [o sea la cañada del río Piaña] que llegaba a unos arboles de çapotes questaban en un cerrillo alto junto a la dicha quebrada que dijeron llegar alli los terminos de la estancia de Santa Maria y los de la estancia de San Xpobal y por ençima de la dicha quebrada avia otros dos çerros nonbrados Ytuyña y el otro Ytuyagua que heran del dicho pueblo de Santa Maria y por mas arriba otro çerro nonbrado Yucucuy que parte terminos con el pueblo de Texupa y este de Santa Maria que todos los dichos yndios por la dicha lengua se $[\mathrm{r}]$ tierras y guerta y arboles del dicho pueblo de Santa Maria.

Como vimos antes en este texto, San Cristóbal reclamaba en su título de sólo tres días después: "[partir] terminos con el pueblo de Santa Maria [en un serro] que se llama Yucutiyagua y con el pueblo de Texupa [ $\left.{ }^{*} \mathrm{en}\right]$ otros dos serros nombrados Tuuyña y Tutuyeque". El conflicto parece reducirse aquí a Itnuina, "loma del perro".

Es sabida la importancia que los documentos pictográficos tienen a veces para las comunidades en la defensa de sus territorios. Sin embargo, en este caso, los dos lienzos de Nativitas y Otla ilustran que no siempre ayudan a aclarar la situación. De hecho, podemos cuestionar si estos documentos autoritativos representan una situación "original" o "primordial" de valor absoluto. Más bien, parece que estos documentos fueron hechos en un momento particular en la historia de las comunidades, poco después de la conquista, cuando éstos pasaron por una serie de cambios importantes que hicieron necesaria la definición de sus límites. No se trata entonces de un periodo de estabilidad o de consenso entre comunidades, sino de un periodo de pugnas y discusiones en que los gobernantes de los yuhuitayu trataron de ponerse de acuerdo sobre las características de sus comunidades. Por lo tanto, el origen de este traslape debe buscarse posiblemente en los cambios en la organización del espacio en el señorío de Coixtlahuaca. Mientras en un primer momento, desde la época posclásica y las primeras décadas de la Colonia, el sistema consistía de casas de nobles que controlaban ciertos nichos de tierras de cultivos y su gente dentro el gran señorío de Coixtlahuaca, el sistema Colonial fue convirtiendo estas casas nobles en unidades territoriales circunscritas por líneas de mojoneras. Los linderos eran conocidos en la época prehispánico, pero no eran determinantes en definir los yuhuita- 
yu. Desde esta perspectiva, el lienzo parece ser otra ilustración para el proceso de transformación de un sistema basado en relaciones personales (entre el señor y "su" población) hacia un sistema fundado en las relaciones entre una población y su territorio. ${ }^{66}$ La incompatibilidad de estos dos sistemas causó quizás en este caso el traslape de territorios. También el reacomodo de la población en núcleos artificiales como Santa María Nativitas y San Cristóbal (los dos no tenían nombres indígenas durante el siglo XVI, indicando su construcción artificial) puede haber acelerado este proceso, ya que no faltaba quien trató de aprovecharse de las tierras abandonadas.

Quizás, la elaboración del lienzo corresponda a un esfuerzo del grupo de nobles representados en él (o sus descendientes) para definir un territorio al momento de enfrentarse con la congregación en Pocotla. Quizás el documento fue parte de una negociación en la corte indígena de Coixtlahuaca por parte de los nobles de Otla para asegurarse de un cacho de territorio. Sin embargo, sin los documentos específicos, los detalles de esta negociación quedarán en un interrogante. Sin embargo, en términos generales, tanto el Lienzo de Nativitas como el Lienzo de Otla pueden verse como documentos en que las comunidades indígenas de la Colonia trataron de redefinirse como unidades territoriales.

BibLIOGRAFÍA

Anónimo, "Anales de Cuauhtitlán”, en: Códice Chimalpopoca. Anales de Cuauhtitlán y Leyenda de los Soles, México, Universidad Nacional Autónoma de México, [1975].

ByLAND, Bruce E. y John PoHL, "Political Factions in the Transition from Classic to Post-classic in the Mixteca Alta", en: E. Brumfiel y J. Fox, eds., Factional Politics in the New World, Cambridge, Cambridge University Press, 1994, 117-127.

Caso, Alfonso, Interpretación del Códice Gómez de Orozco, México, Talleres de Impresión de Estampillas y Valores, 1954.

${ }^{66}$ Para una discusión sobre este proceso reflejado en los documentos pictográficos, véase van Doesburg 2001. 
"Comentario al Códice Baranda", en: Miscelanea Paul Rivet, Octogenario Dicata, vol. I, México, Universidad Nacional Autónoma de México, 1958, 373-389.

, "Los lienzos Mixtecos de Ihuitlan y Antonio de León", en: Homenaje a Pablo Martinez del Río en XXV Aniversario de la Edición de "Los orígenes americanos", México, INAH, 1961, 237-274.

, Reyes y reinos de la Mixteca, vol. I. México, Fondo de Cultura Económica, 1979.

Chance, John K., "Colonial Ethnohistory of Oaxaca", en: Ronald Spores y Patricia A. Andrews, eds., Supplement to the Handbook of Middle American Indians, vol. 4 (Ethnohistory), Austin, University of Texas Press, 1986.

Doesburg, Bas van, "Los Lienzos Pictográficos de don Francisco Belmar", en: Mexicon, vol. xx (3), 1998a, 52-54.

, "Commercializing Coixtlahuaca history; the twentieth century adventures of the Lienzo de Tlapiltepec", en: Indiana Journal of Hispanic Literatures, 13 (Mexican Codices and Archaeology), Indiana University, 1998b, 59-66.

,"The Origin of the 'Lienzo Tulancingo", en: Ancient Mesoamerica, 11, 2000, 169-183.

, "De Linderos y Lugares: territorio y asentamiento en el Lienzo deSanta María Nativitas", en: Relaciones, 86 (Iconografía y Gobierno Indígena), Zamora, Colegio de Michoacán, 2001, 15-82.

-, Documentos Antiguos de San Miguel Tequixtepec, Oaxaca. Los primeros cien años de la Colonia (1533-1617), cNws Publications, vol. 112, Research School cNws, Leiden University, 2002.

, "El siglo XVI en los Lienzos de Coixtlahuaca", en: Journal de la Société des Américanistes, 89-2, 2003, 67-96.

, "El Códice Lucas Alamán, un documento proveniente de San Miguel Tequixtepec", en: Mexicon, xxvIII (1), 2006, 15-19.

, Coixtlahuaca and the Origins of the Lienzo de Tlapiltepec, manuscrito, en preparación.

Doesburg, Bas van y Olivier van BuRen, "The Prehispanic History of the Valley of Coixtlahuaca, Oaxaca", en: Cuadernos de Historia Latinoamericana, Códices, Caciques y Comunidades, núm. 5. AHILA, 1997, 103160. 
DoEsburg, Sebastián van y Michael Swanton, “Mesoamerican Philology as an Interdisciplinary Study: the Xru Ngiwa 'barrios' of Tamazulapan Oaxaca, Mexico", en preparación.

Durán, Fray Diego de, Historia de las Indias de Nueva España e Islas de la Tierra Firme, Editorial Porrúa, Mexico, 1984.

GERHARD, Peter, Congregaciones de indios en la Nueva España antes de 1570, en: Historia Mexicana, vol. XxvI, núm. 3, México, El Colegio de México, 1977, 347-395.

JANSEN, Maarten, Huisi Tacu. Estudio interpretativo de un libro mixteco antiguo: Codex Vindobonensis Mexicanus I. CEDLA (Incidentele Publicaties, 24, 2 vols.), Amsterdam, 1982.

JANSEn, Maarten y Gabina Aurora Pérez Jiménez, Encounter with the Plumed Serpent. Drama and Power in the Heart of Mesoamerica, University Press of Colorado, Boulder, 2007.

Jarquín Ortega, María Teresa, Congregaciones de pueblos en el Estado de México, Zinacantepec, El Colegio Mexiquense, 1994.

Johnson, Nicholas, "Las líneas rojas desvanecidas en el Lienzo de Tlapiltepec: una red de pruebas", en: Códices y Documentos sobre México, Primer Simposio, Constanza Vega Sosa, ed., INAH, Mexico, 1994, 117-144.

, "The Route from the Mixteca Alta into Southern Puebla on the Lienzo of Tlapiltepec", en: Códices y Documentos sobre México. Segundo Simposio, vol. 1, México, INAH, 1997, 233-268.

KöNIG, Viola, "Der Lienzo Seler II und seine Stellung innerhalb der Coixtlahuaca-Gruppe", en: Baessler Archiv, Neue Folge, vol. XxxII, Berlín, Verlag von Dietrich Reimer, 1986.

___ _Lienzo Seler II and The Coixtlahuaca Group of Lienzos", en: Latin American Indian Literatures Journal , 15(2), 1999, 147-210.

Mendoza García, Edgar, Los bienes de comunidad y la defensa de las tierras en la Mixteca oaxaqueña, México, Senado de la República, 2004.

OuDIJK, Michel, "La toma de posesión: Un tema mesoamericano para la legitimación del poder", en: Relaciones, 91 (Texto y género en las letras novohispanas), Zamora, Colegio de Michoacán, 2002, 95-132.

Ouweneel, Arij, "Altepeme and Pueblos de Indios. Some Comparative Theoretical Perspectives on the Analysis of the Colonial Indian Communities", en: Arij Ouweneel y Simon Miller, eds., The Indian Community of Colonial Mexico, CEDLA, Amsterdam, 1990, 1-37. 
Parmenter, Ross, "20th Century Adventures of a 16th Century Sheet. The Literature on the Mixtec Lienzos in the Royal Ontario Museum", en: Boletín de Estudios Oaxaqueños, 20, Mitla, Museo Frissel, 1961.

,"The Identification of Lienzo A: A Tracing in the Latin American Library of Tulane University", en: Philological and Documentary Studies, vol. II, part 5, Nueva Orleans, Tulane University, Middle American Research Institute, 1970, 181-195.

, "Four Lienzos of the Coixtlahuaca Valley", en: Studies in Precolombian Art \& Archaeology, vol. 26, Washington, Dumbarton OaksTrustees for Harvard University, 1982.

"The Lienzo of Tulancingo, Oaxaca. An Introductory Study of a Ninth Painted Sheet from the Coixtlahuaca Valley", en: Transactions of the American Philosophical Society, vol. 83, parte 7, Filadelfia, The American Philosophical Society, 1993.

, "La Identificación de Tulancingo en el Lienzo de Ihuitlan: una Valiosa Aportación de un Noveno Lienzo del Valle de Coixtlahuaca", en: Constanza Vega Sosa, ed., Códices y Documentos sobre México, Primer Simposio, INAH, Mexico, 1994, 101-115.

, "A Nativitas Ruler List on Lienzo A", en: Constanza Vega Sosa, ed., Códices y Documentos sobre México. Segundo Simposio, vol. 1, INAH, México, 1997, 269-304.

PoHL, John, "Mexican Códices, Mapas, and Lienzos as Social Contracts", en: Elizabeth Hill Boone y Walter D. Mignolo, eds., Writing without Words. Alternative Literacies in Mesoamerica \& the Andes, Durham, Duke University, 1996, 137-160.

QuezadA, Noemí, "Congregaciones de indios y grupos étnicos: el caso del Valle de Toluca y zonas aledañas", en: Revista Complutense de Historia de América (Madrid), núm. 21, 1995, 141-165.

Rincón MAUTNER, Carlos, "A Reconstruction of the History of San Miguel Tulancingo, Coixtlahuaca, Mexico, from Indigenous Painted Sources", en: Texas Notes, núm. 64, Austin, University of Texas, 1994.

, "The Nuiñe codex from the Collosal Natural Bridge on the Ndaxagua: an early pictographic text from the Coixtlahuaca Bassin", en: Institute of Maya Studies Journal, vol. 1-2, Miami, 1995, 39-66.

, "The history of Place-becoming in the Coixtlahuaca codices", en: Messages and meanings; Papers from the Twelfth Annual Symposium. 
Latin American Indian Literatures Association, Mary Preuss, ed., Lancaster, Labyrinthos, 1997, 129-148.

, Man and the Environment in the Coixtlahuaca Basin of Northwestern Oaxaca, Mexico: Two thousand years of historical ecology, tesis de doctorado, Austin, University of Texas, 1999.

, "La reconstrucción cronológica del linaje principal de Coixtlahuaca", en: Constanza Vega Sosa, ed., Códices y Documentos sobre México. Tercer Simposio Internacional, México, INAH, 2000, 25-44.

, "A Study of the Lienzo de San Jerónimo Otla from the Coixtlahuaca Basin of Oaxaca, Mexico", en: Latin American Indian Literatures Journal, 23 (1), 2007, 74-95.

Sмiтн, Mary Elizabeth, Picture Writing from Ancient Southern Mexico. Mixtec Place Signs and Maps, Norman, University of Oklahoma Press, 1973.

SPORES, Ron, An Archaeological Settlement Survey of the Nochixtlan Valley, Oaxaca, Vanderbilt University Publication in Anthropology 1, Nashville, Vanderbilt University, 1972.

StePhens, John y Robyn McCallum, Retelling Stories, Framing Culture: Traditional Story and Metanarratives in Children's Literature, Nueva York, Routledge, Taylor and Francis Inc., 1998.

TerRaCiano, Kevin, The Mixtecs of Colonial Oaxaca. Nuudzahui history, sixteenth through eighteenth centuries, Stanford University Press, 2001.

TORQUeMADA, fray Juan, Monarquía Indiana, 3 vols., México, Editorial Porrúa, 1986 [1615].

FECHA DE RECEPCIÓN DEL ARTí́CULO: 23 de mayo de 2009

FECHA DE ACEPTACIÓN Y RECEPCIÓN DE LA VERSIÓN FINAL: 4 de enero de 2010 